\title{
From Letter to Twitter: A Systematic Review of Communication Media in Negotiation
}

\author{
Ingmar Geiger ${ }^{1}$
}

Published online: 26 February 2020

(c) The Author(s) 2020, corrected publication 2021

\begin{abstract}
With the advent of modern communication media over the last decades, such as email, video conferencing, or instant messaging, a plethora of research has emerged that analyzes the association between communication media and negotiation processes and outcomes. In this paper, the author systematically reviews theoretical vantage points on communication media and negotiation and summarizes empirical findings from the last six decades. Specifically, the author focuses on three different strategic communication theories and four social psychological theoretical perspectives that found traction in negotiation research. Subsequently, empirical evidence on communication media and negotiation is presented, derived from an extensive literature search of relevant peer-reviewed articles. The author analyzes effects of communication media on the negotiation process (descriptive process parameters, economic reference points, negotiation behavior/tactics, individual perceptual and affective process variables) as well as economic (agreement, individual profit, joint profit, dispersion of profits) and socio-emotional (satisfaction, trust, socio-emotional evaluation of the self and the opponent) outcomes. The discussion takes stock of the current state of research and persisting research gaps, before focusing on some recent developments, and proposing future research avenues.
\end{abstract}

Keywords Communication media $\cdot$ Negotiation process $\cdot$ Negotiation outcome $\cdot$ Media effects

\section{Introduction}

When US president Donald Trump left the 2019 G20 summit in Japan for a bilateral visit to South Korea, he tweeted on June 29: "After some very important meetings, including my meeting with President Xi of China, I will be leaving Japan for South Korea (with President Moon). While there, if Chairman Kim of North Korea sees

Ingmar Geiger

ingmar.geiger@hs-aalen.de

1 School of Management, Aalen University, Beethovenstr. 1, 73430 Aalen, Germany 
this, I would meet him at the Border/DMZ just to shake his hand and say Hello(?)!" Indeed, North Korea's ruler Kim Jong Un replied favorably to this message, and eventually Trump became the first US president to set foot on North Korean soil on June 30th 2019. While this visit to North Korea may have been little less than a much commented event on TV around the globe that day without much further movement towards some sort of agreement between the US and North Korea, the US president's choice and use of a certain communication medium, Twitter, in a negotiation situation may be remembered as a hallmark in the way negotiators use media in present days.

Starting in the late 1960s, negotiation researchers have begun to analyze potential influences of the communication medium in negotiation (Morley and Stephenson 1969; Smith 1969), but they certainly could not have imagined medium use as deployed by US president Trump in 2019. In fact, probably few other boundary conditions of negotiations have changed and evolved as much as the communication medium over the last six decades, mirrored in respective research activities (e.g., Croson 1999; Geiger and Parlamis 2014; Loewenstein et al. 2005; Purdy et al. 2000; Sheffield 1995; Short 1974). Starting with traditional face-to-face (FTF) and written communication (letters), telegraph, telephone, and telefax were added in the nineteenth century as available communication media, video conferencing following as early as the late 1920s (Angiolillo et al. 1993). With the advent of the publicly available internet in the 1990s, and one decade later with mobile internet, email, chats, instant messaging and social media like Twitter and Facebook seem to have largely changed the way people communicate and use communication media in their negotiations today. With artificial intelligence growing out of infancy, a potential new aspect to communication media and their use in negotiation is set to arrive.

The goal of the present article is hence to take stock of the current knowledge on the impact of communication media in negotiation in a systematic review and to derive new research needs from this status quo. To this end, after exposing the literature search and inclusion methodology, the author first presents and discusses three strategic communication theoretical perspectives on the usefulness of different communication media in negotiation as well as four social psychological perspectives that have been evoked in connection with communication media in negotiation. Second, the author reviews and synthesizes empirical evidence about the influence of communication media on negotiation processes and outcomes. In the discussion section, the author summarizes the current state of research as well as persisting research gaps, exposes recent developments, and suggests avenues for future research.

\section{Methodology}

To locate research dealing with the communication medium in negotiation, an extensive literature search was performed, ending in mid-2019. Search terms such as "communication medium" AND negotiation OR bargaining, e-negotiation, "face-to-face" served as identifiers for potentially relevant work. The search included the following databases: Business Source Premier (through EBSCO), Google Scholar, Jstor, 
PsychArticles (through EBSCO), ScienceDirect and SpringerLink. Additionally, reference lists of four meta-analyses dealing with various, specific aspects of communication media in negotiation and related fields (Baltes et al. 2002; Stuhlmacher and Citera 2005; Stuhlmacher et al. 2007; Swaab et al. 2012) provided additionally relevant articles.

Prior research was included in the review of empirical studies when it fulfilled the following criteria: First, it had to be an article from a peer-reviewed scholarly journal. Dissertation monographs or conference proceedings were excluded, because their accessibility and availability varies widely, leading to potential bias. Also, their content (data and theory) often features in more thoroughly worked out journal papers later, too. Second, the research reported in an article had to refer to negotiation. Such a focus excluded mediation, online dispute resolution, group decision making tasks, or interdependent bargaining games. While all aforementioned topics are in one way or another related to negotiation, drawing a line was necessary to get to grips with the sheer number of located articles. Moreover, meta-analytical reviews already exist at least on communication media in group decision making (e.g. Baltes et al. 1992; Swaab et al. 2012) and bargaining games (e.g. Balliet 2009). Third, the research either had to compare negotiation in two or more different communication media or focus on certain specificities within one communication medium, e.g. within text-based electronic communication such as email. The reported theoretical perspectives were included according to their development and use in empirical studies. Hence, purely theoretical perspectives with no empirical test do not feature in this review.

\section{Theoretical Perspectives on Communication Media in Negotiation}

Over the last decades, a number of theories have evolved in different academic disciplines that try to explain which communication medium is best suited for different communication needs and situations. This article considers three strategic communication theories that probably had the most profound impact on negotiation research: media richness theory and the task/media fit hypothesis (Daft and Lengel 1986; McGrath and Hollingshead 1993), grounding in communication (Clark and Brennan 1991), and media synchronicity theory (Dennis et al. 2008). While the strategic communication theories focus on characteristics of media and tasks, the subsequent social-psychological perspectives put the communicator-medium interaction center stage. Under these viewpoints, a medium may help or hinder certain social processes important to the communicators. Most widely cited are the barrier effect (Lewis and Fry 1977; Carnevale et al. 1981), social presence theory (Short et al. 1976), social information processing theory (Walther 1992, 1994), and the communication orientation model for negotiation and group decision making (Swaab et al. 2012). 


\begin{tabular}{|llllll|}
\hline & \multicolumn{5}{c}{ Information \& media richness } \\
\cline { 2 - 6 } Medium & Face-to-face & Telephone & Written, personal & Written, formal & Numeric, formal \\
Feedback & Immediate & Fast & Slow & Very slow & Very slow \\
Channel & Visual, audio & Audio & Limited visual & Limited visual & Limited visual \\
Source & Personal & Personal & Personal & Impersonal & Impersonal \\
Language & Body, natural & Natural & Natural & Natural & Natural \\
\hline
\end{tabular}

Fig. 1 Media richness and media characteristics (Daft and Lengel 1984)

\subsection{Strategic Communication Theories}

\subsubsection{Media Richness Theory and the Task/Media Fit Hypothesis}

Media richness theory was developed by Daft and Lengel $(1984,1986)$ based on the premise that information can be characterized as possessing different degrees of richness. The authors define richness as the potential information carrying-capacity of data (Daft and Lengel 1984) that enables a change in understanding in a given time interval (Daft and Lengel 1986). In turn, communication media determine the richness of information processed. The authors' focus lies on communication and information processing within organizations, so that they restrict their theory development to the most common communication media available for organizational communication at the time: face-to-face (FTF), telephone, letters, written documents, and numeric documents. Those differ in their degree of (1) feedback capability, (2) communication channels utilized, (3) source, and (4) language. Figure 1 exhibits the different communication media, their characteristics, and their richness.

In developing their framework further, Daft and Lengel (1986) focus on media richness as a criterion to handle uncertainty and equivocality of decision situations. They understand uncertainty as the absence of information and conceptualize equivocality as ambiguity, the existence of multiple and conflicting interpretations of a situation, confusion, and a general lack of understanding. In sum, they propose that for situations with high uncertainty and low equivocality, communication media and procedures with low degrees of information richness are suitable, whereas for resolving high equivocality, rich media, such as FTF conversations or group meetings, are needed.

While Daft and Lengel $(1984,1986)$ in their theoretical writings focus more on organizational design when discussing information richness and media richness, McGrath and Hollingshead (1993) put group decision making center stage. They delineate different tasks that work groups typically fulfill: Generating plans and ideas (generate), intellective and decision making tasks (choose), cognitive conflicts and mixed-motive tasks (negotiate), and performance/psycho-motor and contest/ competitive tasks (execute). The authors speculate that the different types of tasks 


\begin{tabular}{|c|c|c|c|c|c|}
\hline & \multirow[b]{2}{*}{ Medium } & \multicolumn{2}{|c|}{ Media richness } & \multirow[b]{2}{*}{ Audio systems } & \multirow[b]{2}{*}{ Computer systems } \\
\hline & & Face-to-face & Video systems & & \\
\hline & Task type & & & & \\
\hline \multirow{4}{*}{ 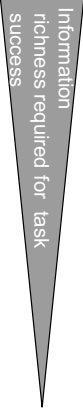 } & $\begin{array}{l}\text { Negotiating } \\
\text { conflicts of interest }\end{array}$ & Good fit & $\begin{array}{l}\text { Marginal fit: } \\
\text { medium too } \\
\text { constrained }\end{array}$ & $\begin{array}{l}\text { Poor fit: medium } \\
\text { too constrained }\end{array}$ & $\begin{array}{l}\text { Poor fit: medium } \\
\text { too constrained }\end{array}$ \\
\hline & $\begin{array}{l}\text { Choosing preferred } \\
\text { answer: judgment } \\
\text { tasks }\end{array}$ & $\begin{array}{l}\text { Marginal fit: } \\
\text { info too rich }\end{array}$ & Good fit & Good fit & $\begin{array}{l}\text { Poor fit: medium } \\
\text { too constrained }\end{array}$ \\
\hline & $\begin{array}{l}\text { Choosing correct } \\
\text { answer: intellective } \\
\text { tasks }\end{array}$ & $\begin{array}{l}\text { Poor fit: info } \\
\text { too rich }\end{array}$ & Good fit & Good fit & $\begin{array}{l}\text { Marginal fit: } \\
\text { medium too } \\
\text { constrained }\end{array}$ \\
\hline & $\begin{array}{l}\text { Generating ideas } \\
\text { and plans }\end{array}$ & $\begin{array}{l}\text { Poor fit: info } \\
\text { too rich }\end{array}$ & $\begin{array}{l}\text { Poor fit: info too } \\
\text { rich }\end{array}$ & $\begin{array}{l}\text { Marginal fit: info } \\
\text { too rich }\end{array}$ & Good fit \\
\hline
\end{tabular}

Fig. 2 The task/media fit hypothesis (McGrath and Hollingshead 1993)

require different levels of information richness to be successfully and efficiently fulfilled. Subsequently, they match information richness of different media-FTF, video systems, audio systems, computer systems, in descending order of information richness - to required information richness of the tasks to arrive at the task/media fit hypothesis: Negotiating conflicts of interest requires the highest amount of information richness and is hence served best by FTF communication, whereas generating plans and ideas could be best served by computer systems, the least rich medium in their considerations.

As Fig. 2 shows, the task/media fit hypothesis presumes that information richness requirements of typical tasks in group decision making should best be matched with a communication medium of a corresponding level of information richness. According to this reasoning, negotiation is best served by FTF communication.

Media richness theory and the task/media fit hypothesis have been used as the theoretical basis for a number of empirical papers analyzing the influence of communication media on the negotiation process and negotiation outcomes (e.g., Mennecke et al. 2000; Purdy et al. 2000; Sheffield 1995; Suh 1999). Their specific findings are discussed in Sect. 4; however, overall support for this theoretical vantage point has been mixed.

\subsubsection{Grounding in Communication}

A rather different theoretical approach to the impact of communication media on negotiation has been laid out in Clark and Brennan's (1991) foundational paper on grounding in communication. The two psycholinguists focus on conditions that allow grounding, a process that leads communicators to share a common ground so that they can be sure that what has been said has been understood. Evidence in grounding can come in the form of negative evidence-the receiver in 
communication shows s/he has not understood what was meant and the sender has to repeat his/her message-or in the shape of positive evidence: verbal acknowledgements (often in utterances such as mm, uuh, umh, ...), relevant next turns (a message building upon what has been correctly understood), or in the form of continued attention. Clark and Brennan (1991) also argue that communicators act according to the principle of least collaborative effort: "The participants try to minimize their collaborative effort-the work that both do from the initiation of each contribution to its mutual acceptance." (p. 136).

The authors especially focus on two conditions for grounding: purpose, i.e. what the communicators try to achieve in their communication, and the communication medium, including the techniques available in the medium to achieve the purpose, as well as its associated costs. With regard to the general purpose of communication, the techniques used for achieving grounding should change, e.g. whether the purpose of the conversation is to plan a party or to arrive at a negotiated agreement. The authors exemplify different techniques for the purpose to reach grounding on a reference object: Among others, the sender could use alternative descriptions of the object, indicative gestures (e.g., pointing at the object of interest), or referential installments, i.e. naming the object before starting to characterize it.

The most important factor determining available techniques for grounding and their associated cost is the communication medium. In combination with the principle of least collaborative effort to reach grounding, Clark and Brennan (1991) propose that communicators choose a medium or media that offer the most suitable and most cost-efficient techniques to reach grounding for a given communication purpose. Table 1 exhibits different media characteristics of four important media in negotiation that determine the success and cost of grounding for different communication purposes.

The different media and their characteristics are associated with different types of costs to reach grounding. In a given communication instance, communicators need to trade off these different costs. Some costs accrue to the sender, some to the receiver, and some to both.

In negotiation research, Clark and Brennan's work on grounding and the different media characteristics spelt out in their article have been mainly used to differentiate email and other asynchronous communication media from synchronous media, mainly FTF interaction. Friedman and Currall (2003) built their theoretical disputeexacerbating model of e-mail around those characteristics. Their model has been taken up in turn by Pesendorfer and Koeszegi (2006) to delineate different behavioral styles in synchronous and asynchronous electronic negotiations. Other empirical research based on grounding in communication includes Cooper and Johnson (2014), Damian et al. (2008), Geiger (2014), Johnson and Cooper (2009a, 2009b), Parlamis and Geiger (2015), or Yuan et al. (2003).

\subsubsection{Media Synchronicity Theory}

The last communication theoretical vantage point on communication media in negotiation in this review is media synchronicity theory, formulated by Dennis et al. (2008). Their prime assumption is that in order to allow mutual understanding in 


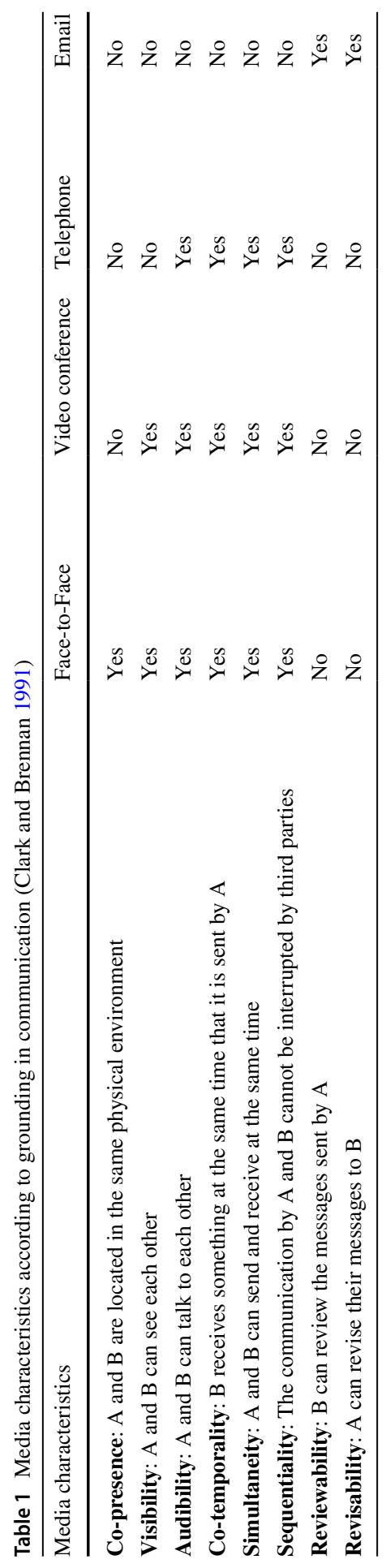


communication, two prototypical communication subprocesses are needed, conveyance of information and convergence on meaning. Conveyance processes entail the transmission of a diversity of new and relevant information so that the receiver is able to build or revise a mental model of the situation. In convergence processes, the discussion and interpretation of the communicators' pre-processed information takes center stage. The goal then is to reach mutual understanding and to agree that mutual understanding has been reached.

Every instance of communication requires a certain amount of both subprocesses, conveyance and convergence. In order for those subprocesses to be successful, one interpersonal and one intrapersonal process need to be accomplished: Information transmission requires preparing, sending, and receiving the information, while information processing is about understanding the meaning of information and integrating it into a mental model.

Media synchronicity theory then proposes that the communication subprocesses' need for information transmission and information processing should be matched to information transmission and information processing capabilities of the communication media. Dennis et al. (2008) define media synchronicity as "the extent to which the capabilities of a communication medium enable individuals to achieve synchronicity" (p. 581). They further propose that synchronicity "exists among individuals when they exhibit a shared pattern of coordinated synchronous behavior with a common focus" (p. 581). Convergence processes benefit from synchronicity, the theory's central construct, while conveyance processes don't.

In essence, the theory proposes that convergence processes have a greater need for rapid information transmission than for information processing. In order to reach mutual understanding, high synchronicity allows more, shorter, and simpler messages, quick back-and-forth exchanges to verify that what has been said has been understood. These exchanges are best supported by communication media with a high level of synchronicity.

The opposite is true for conveyance processes: The level of interaction between the communicators is lower and there is generally more time between messages. For conveyance to happen, the sender of a message may think hard about how to craft a message and the receiver can take time to decode and make sense of the new information conveyed. Allowing the receiver time to deliberate on the meaning of the new information should be more beneficial than potentially feeling pressure to respond quickly. Therefore, media synchronicity theory proposes that conveyance processes are best accomplished with lower synchronicity media.

In order to characterize media into different degrees of synchronicity, Dennis et al. (2008) propose to regard five characteristics, that have been partly considered in media richness theory and grounding in communication, too. Symbol sets expresses the amount of different ways a message can be encoded, encompassing channel and language from media richness theory as well as co-presence, audibility, and visibility from grounding in communication. Transmission velocity describes the speed at which the message can be sent from sender to receiver, touching on the aspect of feedback in media richness theory and co-temporality of grounding. A great symbol set as well as high transmission velocity lead to a high level of media synchronicity. Rehearseability characterizes the extent to which 
a message can be edited and fine-tuned before sending (resembling reviseability in grounding), and reviewability describes the receiver's ability to reexamine or reprocess the message during decoding, either during communication or after the event has passed. The greater rehearseability and reviewability are, the lower is media synchronicity. Finally, parallelism defines the number of possible parallel transmissions of a message. Table 2 summarizes media characteristics and the associated level of media synchronicity of four important communication media in negotiation.

Beyond the central tenet of media synchronicity theory-high synchronicity media are better suited for convergence processes, low synchronicity media for conveyance processes - the authors also speculate about communicator-media and task-media interactions. More specifically, they propose that if communicators are either familiar with the medium and a specific communication task or with a particular communication partner, the need for media synchronicity in these communication instances may be alleviated. Finally, while the original theory was directed to explain communication performance in conveyance and convergence processes, Dennis et al. (2009) subsequently also apply the theory to communication media choice.

Since media synchronicity theory was later proposed than media richness theory and grounding in communication, its application to negotiation research has been less frequent than the earlier media richness theory. Nevertheless, some of the more recent papers dealing with communication media in negotiation have taken up the ideas spelt out in media synchronicity theory (Arthi 2009; Calefato et al. 2012; Damian et al. 2008; Geiger 2014; Geiger and Parlamis 2014; Parlamis and Geiger 2015). Recently, Geiger and Laubert (2018) tested media synchronicity theory's predictions on communication medium choice in two experimental scenario-based studies for which they disentangled different communication subprocesses in negotiation and had them rated according to their degree of conveyance and convergence.

\subsection{Social Psychological Theories}

\subsubsection{The Barrier Effect in Negotiation}

Early works have discussed and empirically analyzed what happens in an integrative negotiation when negotiators can talk to but not see each other, e.g. because they are separated by a visual barrier (Arunachalam and Dilla 1992, 1995; Carnevale and Isen 1986; Carnevale et al. 1981; Fry 1985; Lewis and Fry 1977). This barrier effect precludes negotiators from transmitting, receiving, and interpreting visual cues. The latter are often important in distributive, forcing negotiation tactics, when one negotiator not only tries to dominate the opponent verbally, but also attempts to "stare him/her down". Since the barrier prevents visual cues such as gazing and staring, the related verbal dominance attempts also become less pronounced. Overall, a visual barrier thus prevents excessive distributive negotiation behavior and should in turn promote more integrative outcomes (Carnevale et al. 1981). 


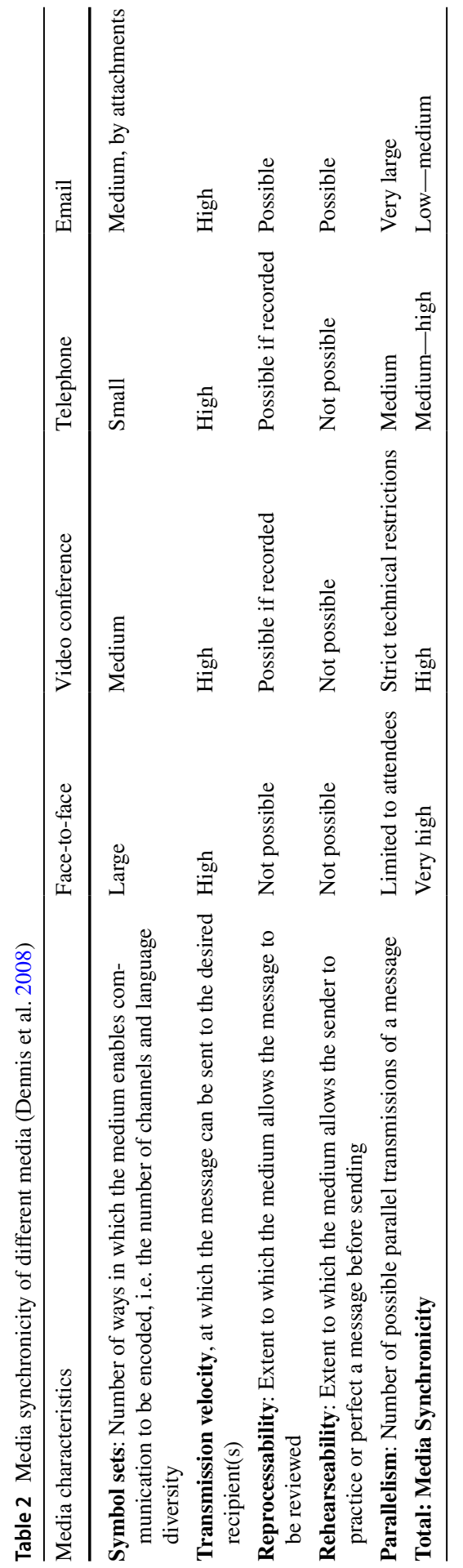




\subsubsection{Social Presence Theory}

Social presence theory (Short et al. 1976) or the psychological distance perspective takes an opposite stand (Citera et al. 2005; Stuhlmacher and Citera 2005). Under this viewpoint, other communication media than FTF lack in social presence or the bandwidth of various communication channels (in the words of media richness theory), the number of media characteristics (grounding in communication), or the broadest symbol set (media synchronicity theory). Related theoretical reasoning includes "reduced social cues" (Kiesler and Sproull 1992; Sproull and Kiesler 1986) and "social impact theory" (Latané 1981). The greater this lack of media features, the smaller becomes the social presence and the greater becomes the psychological distance between negotiators due to a number of reasons (Dorado et al. 2002; Kiesler et al. 1984; Morris et al. 2002; Stuhlmacher and Citera 2005):

- Lack of social context and subsequent depersonalization (e.g. Sproull and Kiesler 1986),

- Less social presence in terms of the proximity or tangibility of the other person with a subsequent lack of attention to the less socially present other (e.g. Spears and Lea 1994),

- Feelings of psychological distance coupled with weaker interpersonal bonds and less cooperation,

- Less social influence due to decreased immediacy of communication, and

- Less transmission of social emotion and rapport.

Social presence theory and the psychological distance perspective have later been further developed and nuanced, for example by differentiating the salience of individual or social identities of the communicators (Social Identity/De-individuation (SIDE) model, Lea and Spears 1992; Spears and Lea 1994; Swaab et al. 2012). However, the SIDE model's traction in the negotiation literature has been rather small, with greater applicability to the group decision making realm (Swaab et al. 2012).

In sum, social presence theory suggests that other media than FTF are less suited for instrumental communication in negotiation; they eventually lead to suboptimal negotiation processes and outcomes because a number of social-psychological functions of FTF communication are barred by other media. While social presence theory has different roots than media richness theory, when applied to negotiation, they come to very similar conclusions (e.g. Diermeier et al. 2008; Pesendorfer and Koeszegi 2006).

\subsubsection{Social Information Processing Theory}

Social information processing theory was developed by Walther $(1992,1994)$ in regard to findings of social interaction in FTF versus text-based computer mediated communication (CMC). Inferiority of CMC vs. FTF for most types of communication, proposed by media richness theory and social presence theory, did not hold true in a variety of empirical studies, so that theoretical extensions seemed warranted. 
In spelling out social information processing theory, Walther (1992) assumes that humans have a need to affiliate when communicating, i.e., they try to build meaningful and positive relationships with others (Swaab et al. 2012). In order to build such relationships in communication, people have to rely on the (verbal-textual, nonverbal) cues available in the channels of a given communication medium. They use these cues to transmit an impression of themselves to the other communicators (encoding) and to form an impression of the others (decoding). Depending on the number and type of available channels in a communication medium, it takes more or less time to develop psychological-level knowledge of the other person and in turn meaningful relational communication. For media devoid of some channels, such as $\mathrm{CMC}$, it takes longer to establish meaningful relations. Over time, communicators adapt to the available channels and even develop electronic paralanguage to transmit socio-emotional cues (Griessmair and Koeszegi 2009). Moreover, even the anticipation of future interaction may suffice for CMC to establish relational communication quickly (Walther 1994).

Applied to media effects in negotiation, social information processing theory suggests that negotiators using media devoid of some of the channels available in FTF may just need more time to establish relational communication to attain similar results as FTF negotiators (e.g. McGinn and Keros 2002; Suh 1999; Yuan et al. 2003), but they are not generally at a disadvantage.

\subsubsection{Communication Orientation Model for Negotiation and Group Decision Making}

The most recent theoretical development on media in negotiation (and group decision making) from a communication psychological perspective is Swaab and colleagues' (2012) communication orientation model for negotiation and group decision making. Their basic assumption is that information sharing and integration are critical for effective social interaction, including, e.g., comprehension, problem solving, and finding common ground. They further assume that negotiators' approach to information sharing and integration depends on their orientation towards negotiation or group decision making. It is either cooperative, non-cooperative, or neutral. Under a cooperative orientation, negotiators actively seek, share, and integrate information to the benefit of themselves and others. Non-cooperative negotiators, in contrast, only share information for their own benefit and are generally wary of information gained from others.

The communication orientation model then proposes that negotiator orientation interacts with channel attributes of the communication medium to influence information sharing and integration and ultimately negotiation outcomes. Swaab et al. (2012) differentiate three channel attributes: visual channel (y/n), vocal channel $(y / n)$, and synchronicity $(y / n)$. Under this differentiation, the availability of all three channels mostly benefits negotiators with an initially neutral orientation who tend toward cooperation or non-cooperation depending on the other negotiator's orientation. Availability of many channels (e.g. a smile, a nod, "ummh") facilitates the quick establishment of rapport and trust and helps initially neutral negotiators take a cooperative orientation. This perspective is much in line with media richness and 
social presence theory. For cooperative negotiators, the model predicts a limited or no effect of more channels. Cooperative negotiators enter negotiations primed to think the best of their counterpart, because they may have a shared history or identity. In turn, fewer channels do not pose a threat to rapport or trust development, in line with social information processing theory (Walther 1992). Finally, for non-cooperative negotiators, fewer channels may actually be beneficial. When negotiators are non-cooperatively predisposed, many channels have a greater chance to transmit cues that may give the impression to be dominated or exploited, leading to spirals of competitive behavior. This reasoning is in line with the barrier effect (Lewis and Fry 1977; Carnevale et al. 1981).

Swaab and colleagues' (2012) model can be considered the current state of the art with regard to the psychology of communication media in negotiation. In developing it, they also put it to two meta-analytical tests (negotiation, group decision making) and found broad support.

\subsection{Critical Assessment of Theories}

Table 3 exhibits a comparison of the different theories used to explain communication media effects in negotiation. They all share the idea of looking at different media characteristics to develop propositions on communication outcomes in different media.

The communication strategic theories do this under the implicit assumption that communication shall be efficient (e.g. with regard to time, resources) and by focusing mostly on cognitive processes of the communicators. For example, grounding in communication assumes least collaborative effort, the task-media fit hypothesis proposes an information richness fit between task and medium, and media synchronicity theory tries to match communicators' synchronicity with media synchronicity. Overall, these theoretical approaches are predominantly instrumental in that they suggest one optimal medium or a combination of optimal media for a given communication purpose. While the earlier media richness theory does consider neither certain boundary conditions (e.g. related to the communication situation or the person) nor the possibility to combine media, grounding in communication remains unspecific in that regard. Only the later media synchronicity theory proposes both initial boundary conditions (task familiarity, partner familiarity) and explicitly advocates a combination of communication media based on the predominant goal of the communication sub-process, conveyance of information or convergence on meaning. The communication strategic theoretical perspectives also have in common that they are supposed to fit a wide range of communication instances, not only negotiation. Therefore, equating a certain successful negotiation outcome, e.g. joint profit, with a successful communication outcome according to the theories' understanding can be problematic and may account for some of the contradictory findings when media richness theory was empirically tested.

The social-psychological theories try to explain communication task processes and outcomes by characteristics of the social circumstances, i.e. the social psychological dealings between the communicators and the socio-emotional and cognitive processes 


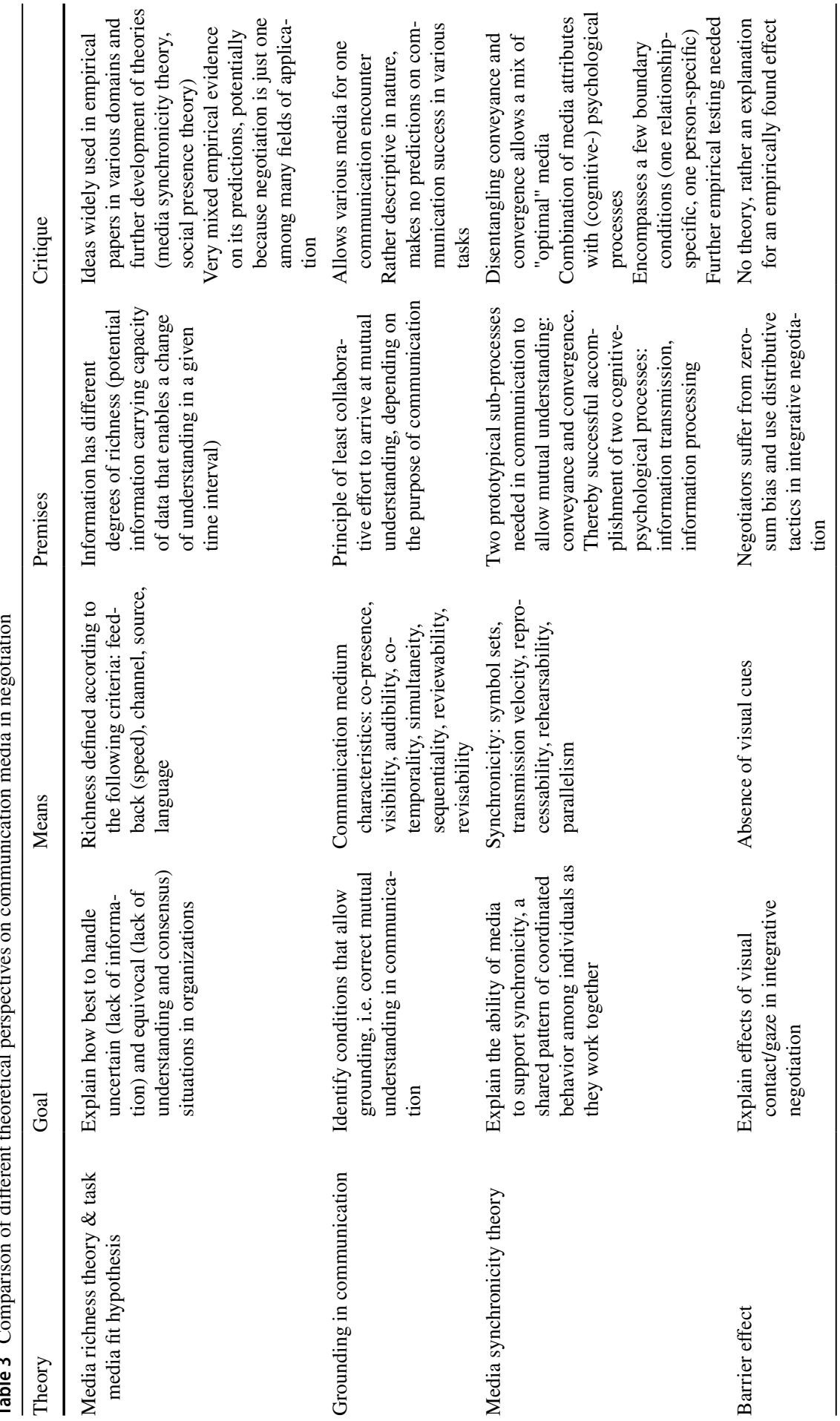




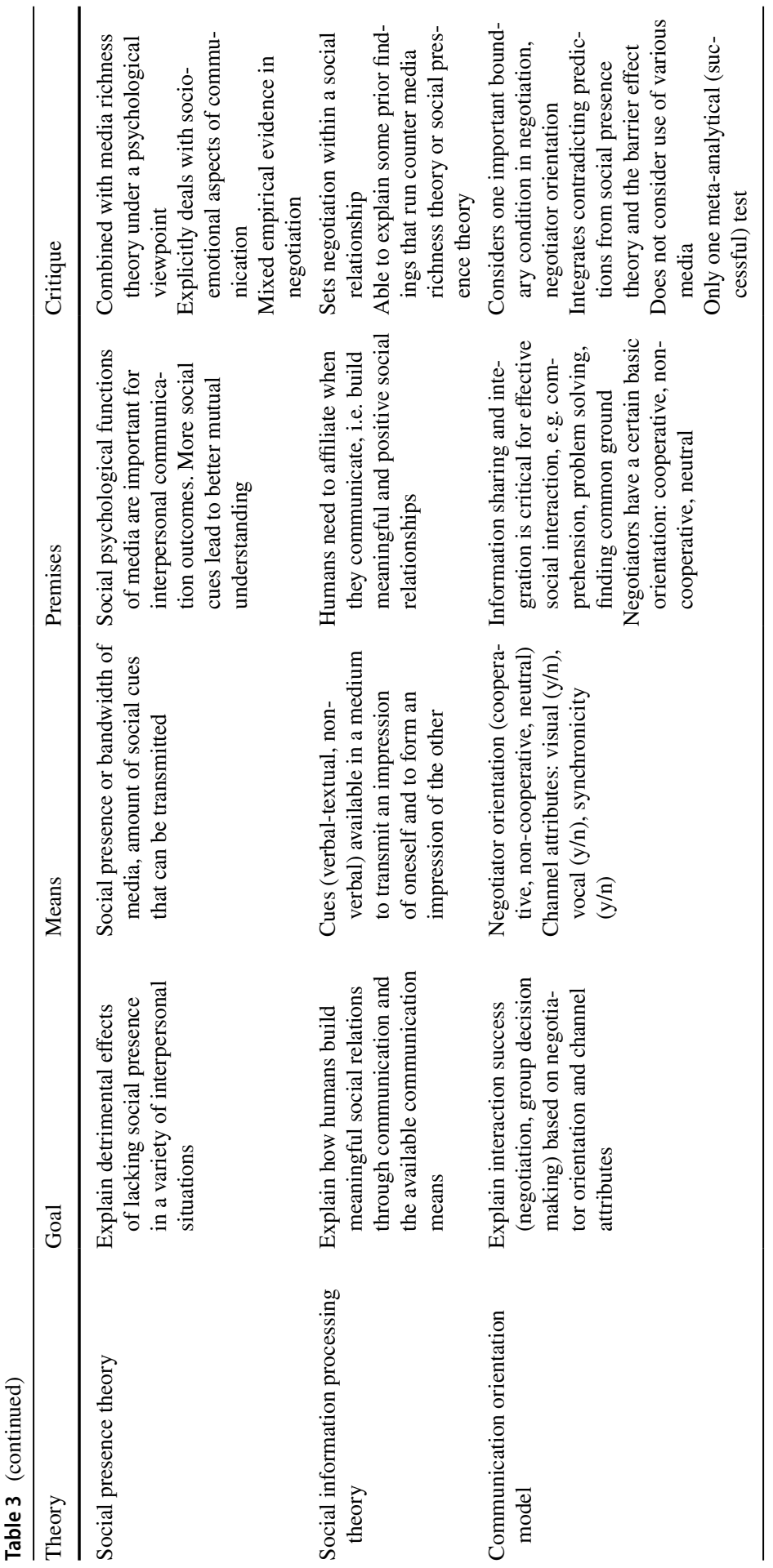


within each actor. The reviewed theoretical perspectives do this either with a wide focus of application (social presence theory, social information processing theory) or with a narrow one on negotiation (barrier effect, communication orientation model). The younger theories (social information processing theory, communication orientation model) also seek to integrate contradictory past findings by introducing meaningful boundary conditions, i.e. time available to communicators (social information processing theory) and negotiator orientation, reconciling the predictions of the barrier effect and social presence theory.

In summary, the assessment of the different theoretical perspectives shows a development over the last decades. This includes the formulation of boundary conditions, which are in some instances able to reconcile formerly seemingly disparate findings. The social-psychological theoretical perspectives highlight the need to assess not only instrumental, cognitive processes, but also social psychological and socio-emotional ones, a benefit over the communication strategic theories. So far, however, they make no explicit predictions on communication media combinations, i.e. a number of media used consecutively or in parallel. That aspect features prominently in media synchronicity theory, as does a specification of what "task" in communication can be thought of, namely the sub-processes of conveyance on convergence.

Looking ahead, further theoretical development needs to take into account and integrate at least the following four theoretical building blocks: social psychological aspects, meaningful boundary conditions, correspondence between general communication outcomes and specific negotiation processes and outcomes, and communication media combinations instead of single media only. Social psychological aspects include, e.g., the development of trust and rapport, affective processes of the negotiators (Moore et al. 1999), and the development of social relationships (Walther 1992). Meaningful boundary conditions could encompass communicator-medium attitudes (Geiger and Parlamis 2014), negotiator incentive structures (Barkhi et al. 1999, 2004), or negotiation difficulty (e.g. Huang et al. 2008; Wang and Doong 2014). A closer elaboration of the correspondence between general communication outcomes such as mutual understanding, synchronicity, or grounding with negotiation processes, e.g. behavior, offer patterns, and outcomes, e.g. joint profit, also seems warranted. For instance, if negotiators reach mutual understanding on positions, but not on interests, they may very well reach a communicative consensus, but a suboptimal negotiation outcome. Elaboration of how the two communicative sub-processes of conveyance and convergence relate to specific negotiation sub-processes may be but one possible way forward (e.g. Geiger and Laubert 2018). Finally, future theoretical development should take into account the possibility to use various media in sequence and/or in parallel (e.g. Damian 2002).

\section{Empirical Evidence on Communication Media Effects on Negotiation Process and Outcomes}

Table 4 exhibits all 98 empirical studies included in the present review. As the media column shows, they cover a wide variety of communication media. Studies mostly refer to integrative negotiation and to a lesser degree to distributive negotiation as 
well as to group (multi-party) negotiation. Also included are relevant field studies, studies including non-scored negotiation exercises and meta-analyses. The dependent variables column shows the types of dependent variables that the studies report: process measures (e.g. time, behaviors, offer patterns), economic negotiation outcomes (e.g. agreement, individual and joint profit), and socio-emotional outcomes (e.g. satisfaction, trust). Finally, the theories column summarizes which of the above-discussed media-related theories have been used in the articles.

Figures 3, 4 and 5 illustrate the evolution of research interest on communication media in negotiation across the decades. Overall, 25 empirical studies, detected for this review, have been published in the 1960s, 70s, 80s, or 90s. In the subsequent decade, from 2000 to 2009, this number nearly doubled with 49 empirical papers, with 24 following in the 2010s. Regarding the communication media included in the studies (see Fig. 3), FTF seemed to be the standard against which the other media were pitted until the millennium-21 out 25 studies contained a FTF condition. In the 2000s, only 26 out of 49 still contained FTF, while the same amount of studies looked at synchronous CMC, with asynchronous CMC following suit (21 studies). In the 2010s, the latter category drew the most research interest (15 out 24), probably because of a specific concern about email negotiation. Video and audio, in contrast, somehow seemed to have been of less concern to researchers, despite their importance in practice.

Figures 4 and 5, displaying dependent variable categories and dependent variables analyzed in the reviewed studies, show a similar development of changing research interest. In the earlier time interval (1960s to 1990s), a clear emphasis was on economic outcome variables, notably joint profit or a similar dyadic outcome. In the second time interval, negotiation behavior in various conceptualizations became the most often cited dependent variable, possibly because of the greater ease to capture it in written communication, which featured a lot more in the 2000s than before. Figures 4 and 5 also show the lowest interest in socio-emotional outcome variables compared to other outcome variables across all time periods, although relatively speaking analysis of socio-emotional outcomes has increased. This may be due to more recent insights on the importance of socio-emotional outcomes for future relationships between negotiators (e.g. Curhan et al. 2009).

\subsection{Negotiation Process}

\subsubsection{Negotiation Time and Amount of Communication}

Various important process characteristics potentially differ between the communication media. To start with, descriptive process characteristics, such as negotiation time and amount of communication, may differ between communication modes. Overall, synchronous media with an audio channel, such as FTF, video, and telephone were found to need less time for finalizing a negotiation than text-based communication such as email or instant messaging (IM) in the majority of studies reporting negotiation time (Galin et al. 2007; Geiger 2014; Mennecke et al. 2000; Purdy et al. 2000; Scheck et al. 2008; Suh 1999; Wang and Doong 2014; Yang 2012). In 


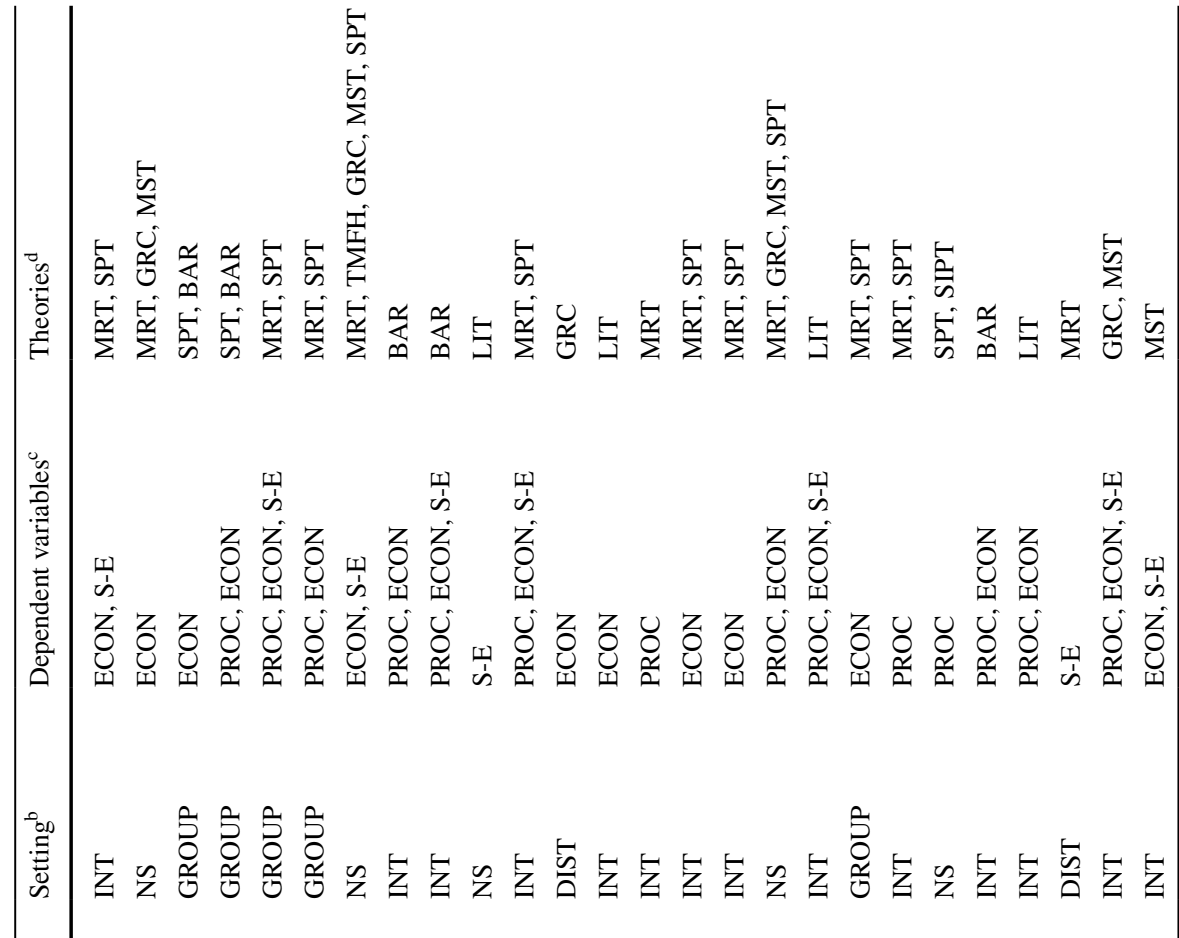

(

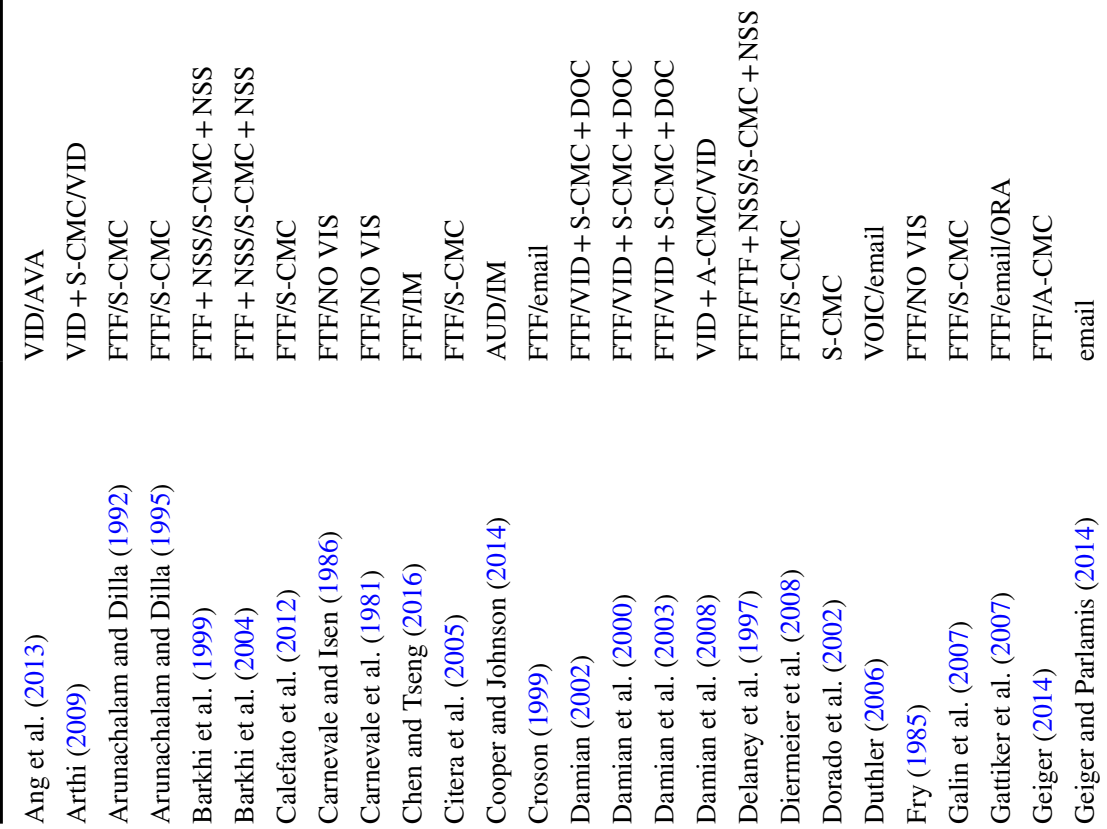




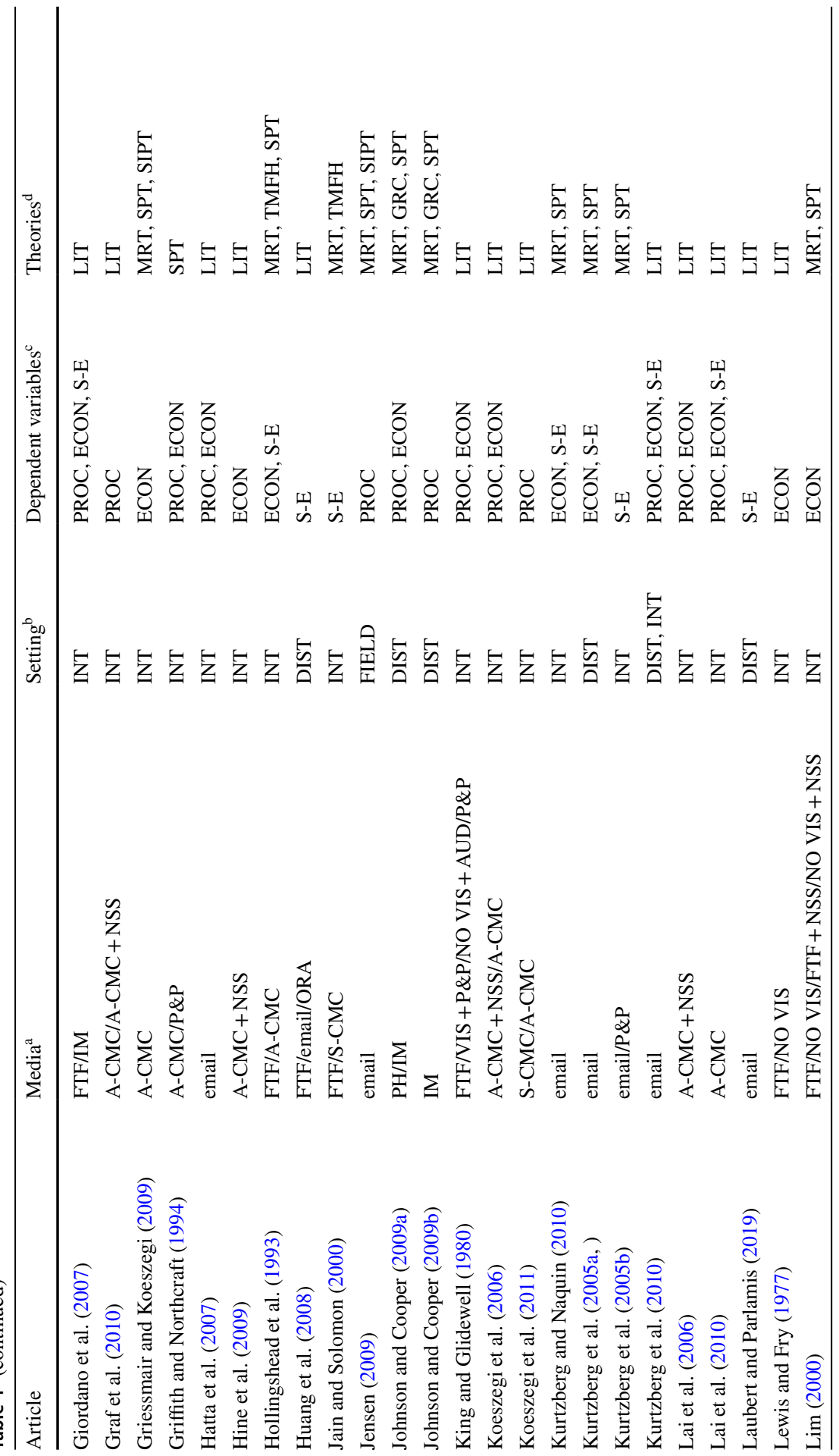




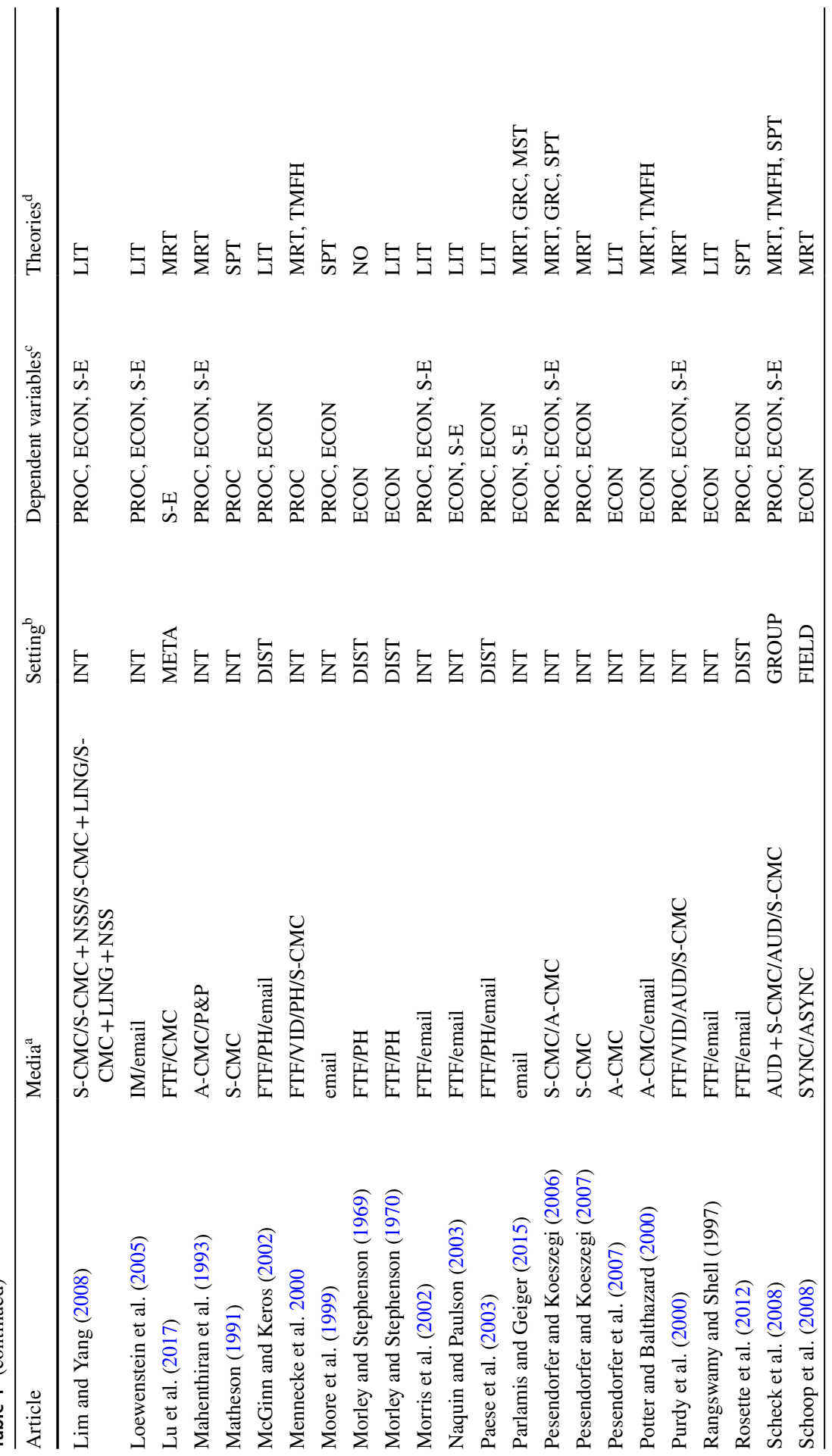




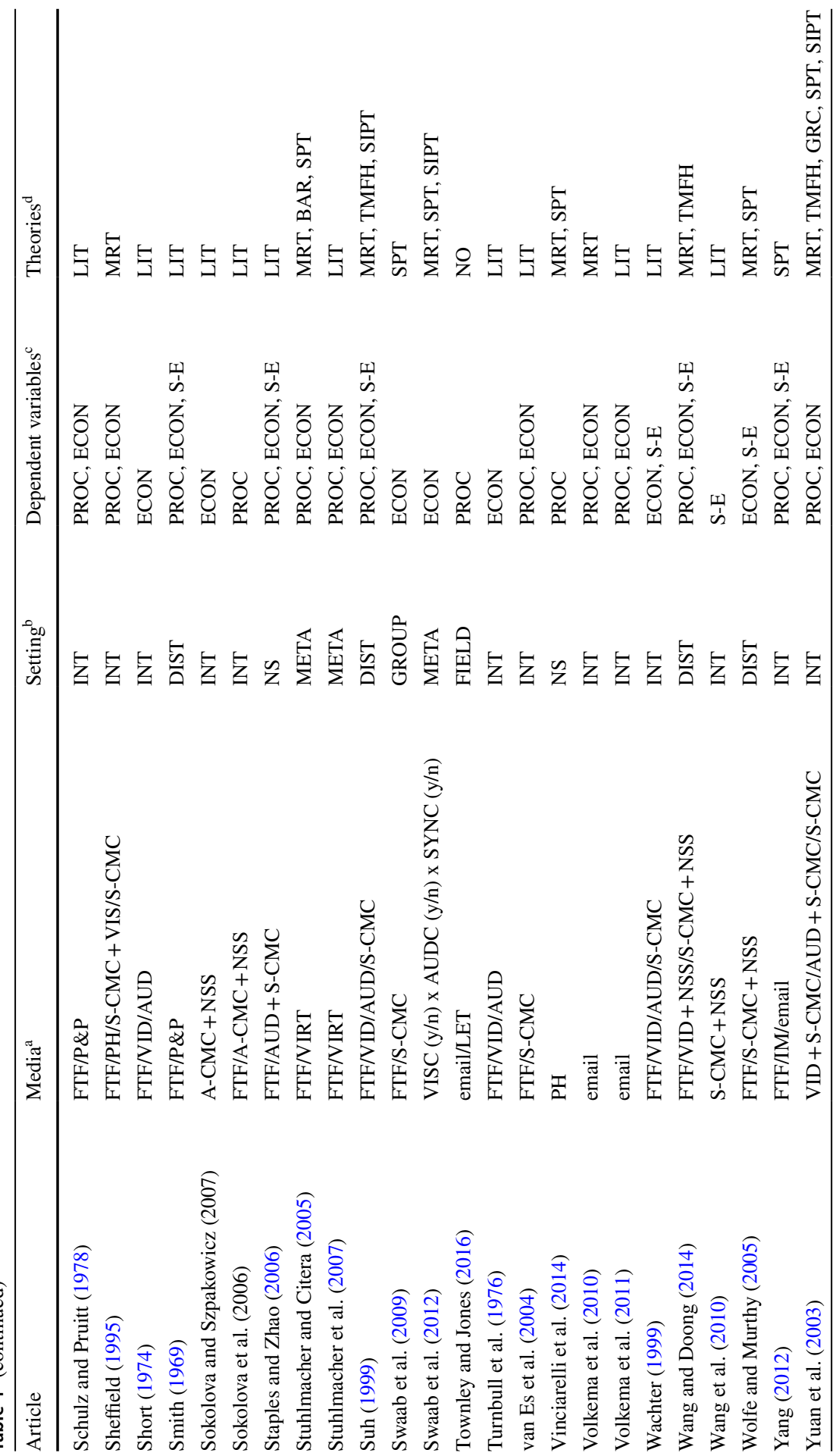




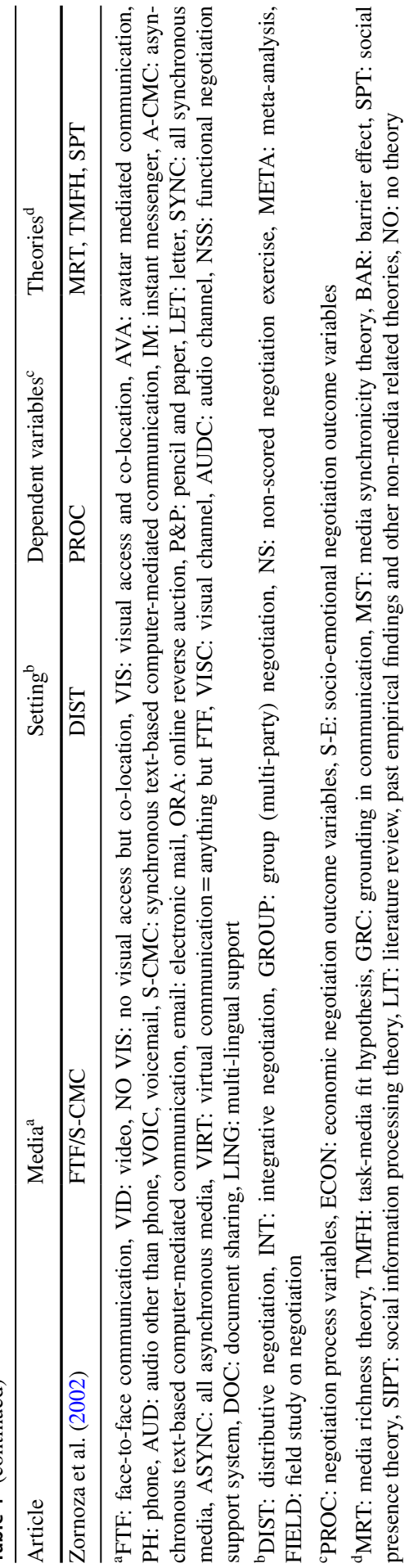




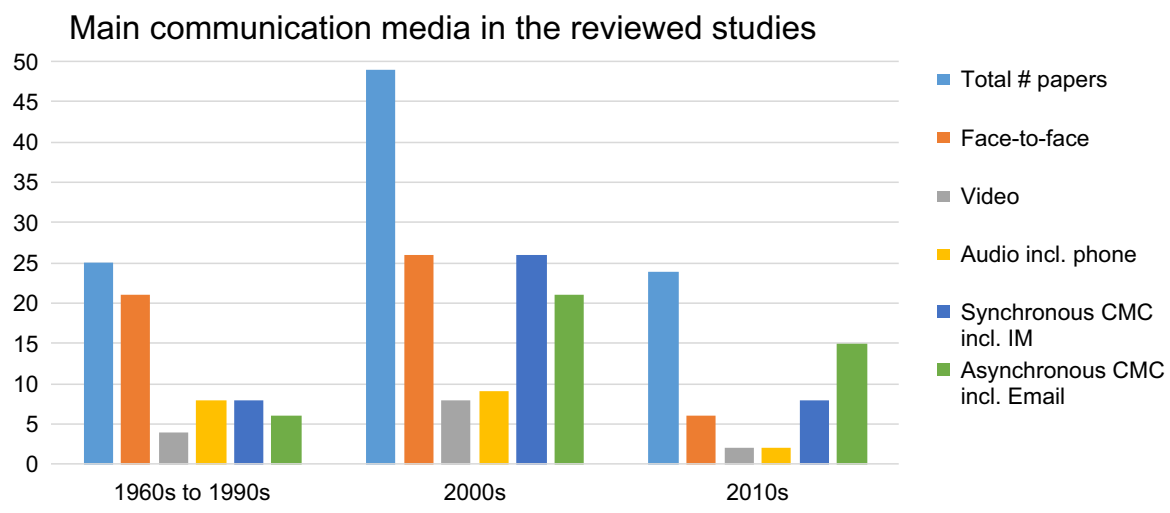

Fig. 3 Main communication media in negotiation studies across different time intervals

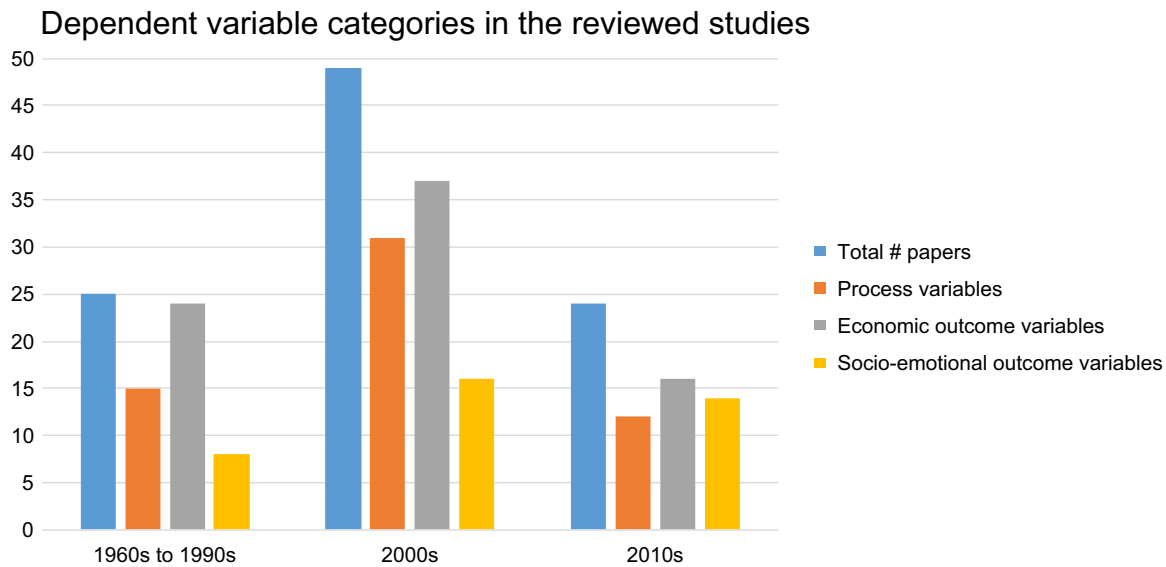

Fig. 4 Dependent variable categories in the reviewed studies across time intervals

a similar vein, computer support made text-based negotiation quicker compared to pencil and paper as witnessed by fewer offer rounds in a study by Mahenthiran et al. (1993). Despite the shorter negotiation time in media with an audio channel, the amount of communication was still higher in those media (King and Glidewell 1980; Sheffield 1995). This finding is also mirrored in synchronous versus asynchronous text-based electronic negotiation, where negotiators using an instant messenger (IM) system (synchronous) communicated more than those using email (asynchronous) when one side (the seller) had intricate (vs. simple) arguments (Loewenstein et al. 2005).

Contrary to these majority findings, other studies report no significant time differences between the various media employed (Barkhi et al. 1999; Delaney et al. 1997; King and Glidewell 1980; Smith 1969; Wang and Doong 2014). While in the studies by Smith (1969) and King and Glidewell (1980) sample sizes were too small 


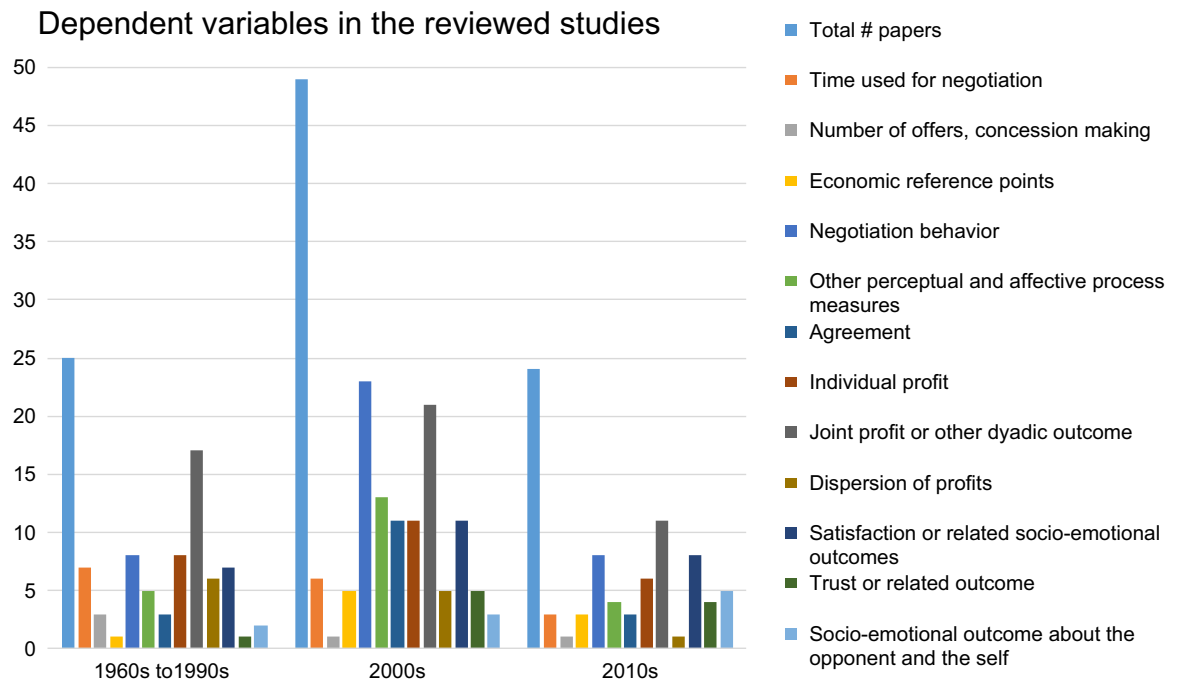

Fig. 5 Dependent variables in the reviewed studies across time intervals

to reach significance of results, Barkhi et al. (1999) speculate that a greater taskorientation or power application of the most powerful party may be responsible for similar negotiation times between FTF and CMC communication. In Delaney and colleagues' (1997) study the time taken to use a functional negotiation support system (NSS) in both FTF and CMC may be responsible for equal negotiation times, and Wang and Doong's (2014) similar finding may be due to the simplicity of their negotiation task (transparent price bargaining). Chinese negotiators in synchronous CMC took more time when they used a native language support tool compared to not using it (Lim and Yang 2008). This may be due to the slower Chinese characters keyboard or eventually because negotiators send more messages and offers in their native (Chinese) compared to a foreign language (English; Lai et al. 2010). When FTF negotiations were supported by a negotiation support system (NSS), they also took longer than without such support (Delaney et al. 1997).

\subsubsection{Number of Offers}

Some articles report the number of offers made in negotiations with different media. From the empirical evidence, no clear picture emerges. Neither Schulz and Pruitt (1978) nor Fry (1985) find main effects for media (FTF, paper \& pencil) on the number of offers or number of different offers, but only interaction effects: Team oriented FTF negotiators (Schulz and Pruitt 1978) and FTF negotiators in high-low Machiavellianism dyads (Fry 1985) make less offers than the other respective negotiators. In the study by Delaney et al. (1997), most offers are made by FTF negotiators who use a NSS, while the number of offers in synchronous CMC plus a NSS is no different from pure FTF negotiators. Lai et al. (2010) report more offers for e-negotiators who negotiate in their native compared to a foreign language. In sum, 
those studies only find media differences on the number of offers under various boundary conditions, but no main effect. An interesting notion is added by Damian and colleagues, who compare video only to video negotiations with preliminary asynchronous $\mathrm{CMC}$ : their results show that in previously unstructured software requirements negotiations, there are less questions per issue, more extra information per uncertainty, and less clarifications per issue in video only compared to video plus preliminary asynchronous CMC.

\subsubsection{Economic Reference Points}

Some studies report important economic reference points such as negotiator aspirations, first offers, and concessions. Geiger (2014) finds lower aspirations in textbased electronically mediated negotiations than in the FTF mode. A different finding comes out of Paese and colleagues' (2003) work, who report higher first offers in email and telephone compared to FTF, when there was no honest disclosure of the opponent's reservation price. Mahenthiran et al. (1993) report higher first offer spreads for CMC compared to pencil and paper negotiations, and Kurtzberg et al. (2010) find more first offers within the bargaining zone in email communication, when the negotiation was preceded by the exchange of a humorous comic strip. Higher first offers were reported for Hong Kong email versus FTF negotiators, but not for US email negotiators (Rosette et al. 2012). These findings suggest that the communication medium may interact with other variables to produce different offer process parameters in different media. Concerning subsequent concession making, Johnson and Cooper (2009b) report lower levels of concessions in IM compared to telephone negotiations. While Schulz and Pruitt (1978) and Fry (1985) report having measured systematic concession making as a predecessor to integrative outcomes, they provide no figures of the variable in their different communication conditions.

\subsubsection{Negotiation Behavior}

With regard to negotiation behavior or tactics, the literature offers partly diverging findings as pertaining to the different communication media. Early works find more cooperative behavior (Carnevale et al. 1981), more trial-and-error processes to find win-win agreements and more insight (Carnevale and Isen 1986) when negotiators are separated by a visual barrier compared to sitting FTF. This finding is contrary to Barkhi et al. (1999, 2004), who report more truthful information exchange in FTF versus synchronous CMC negotiation, both conditions supported by a NSS. Yuan et al. (2003) find that text only CMC is rated worse to gain mutual understanding than text plus audio or video. Pesendorfer and Koeszegi (2006) report more taskrelated information exchange in asynchronous versus synchronous e-negotiations, mostly in early and late phases of the negotiation (Koeszegi et al. 2011). In partial contrast, Galin et al. (2007) report more soft tactics in FTF negotiation than in e-negotiation. Graf et al. (2010) find differences on creating value and integrative information exchange in synchronous CMC negotiations compared with synchronous CMC with NSS support, however, they do not report in which direction the differences play out. A number of papers report no differences regarding various 
integrative behaviors between the different media conditions (collaborative climate: Delaney et al. 1997; problem-solving approach: Yang (2012); positive conflict management: Zornoza et al. 2002; perception of partner's strategy: Griffith and Northcraft 1994).

A visual barrier also seems to inhibit competitive behavior (Carnevale and Isen 1986), a finding mirrored in a study by Geiger (2014) who reports lower levels of various competitive behaviors in IM versus FTF negotiations. Pesendorfer and Koeszegi (2006) find less competitive and unfriendly behavior in asynchronous versus synchronous e-negotiation, mostly toward the beginning and the end of negotiations (Koeszegi et al. 2011). The overall empirical evidence, however, draws a slightly different picture: A meta-analysis finds that FTF negotiations are less hostile than virtual negotiations (Stuhlmacher and Citera 2005), especially for women (Stuhlmacher et al. 2007; see also Matheson 1991 for gender effects in synchronous CMC negotiation) and for strangers (McGinn and Keros 2002). This finding also resonates in later papers such that more hard tactics are reported in e-negotiation than in FTF (Galin et al. 2007) and more forcing behavior in IM than FTF negotiation (Giordano et al. 2007). Loewenstein et al. (2005) report more deception in synchronous (IM) e-negotiation compared to asynchronous (email) e-negotiation when sellers were provided with intricate arguments. However, several authors also report no differences in distributive behaviors or reflections thereof in various communication media (negative conflict management: Zornoza et al. 2002; team conflict: Staples and Zhao 2006; negative climate: Delaney et al. 1997) or do not report in which direction differences exist (Graf et al. 2010). Regarding persuasion or the ability to influence the other party, Yuan et al. (2003) report perceived advantages to influence other negotiators in video or audio plus text compared to text only negotiators. Vinciarelli et al. (2014) find that in phone negotiations, the receiver of the call is more persuasive than the caller. While there is no unambiguous picture about the relative occurrence of cooperative and competitive behavior in different communication media, van Es et al. (2004) report that a behavioral strategy change is easier accomplished in asynchronous (email) than synchronous (FTF) media.

\subsubsection{Perceptual and Affective Process Variables}

Negotiation behavior or tactics is often conceptualized as a dyad-level variable; other papers focus more on individual-level process characteristics. With regard to communicated affect, the literature offers diverging results: While Johnson and Cooper (2009a, 2009b) find less communicated affect in IM than telephone negotiations, Geiger (2014) reports more positive relational messages in asynchronous IM than FTF negotiations. Similarly, Pesendorfer and Koeszegi (2006) find more negative and less positive affect communicated in synchronous versus asynchronous e-negotiation. In a slightly different vein, Duthler (2006) finds that email requests are more polite than voicemail requests.

Pre-negotiation trust, in contrast, seems to be lower for online than FTF negotiators (Naquin and Paulson 2003). This finding is mirrored also in lower self and partner credibility in IM versus FTF integrative negotiation (Citera et al. 2005) as well as higher seller trust in a buyer (benevolence, credibility) in FTF compared 
to email and reverse auctions (Huang et al. 2008). When procurement complexity was high, seller trust was higher in FTF and email than in reverse auctions (Gattiker et al. 2007).

Rapport during negotiation, i.e. "a state of shared positive affect and mutual interest in the dyad" (Moore et al. 1999, p. 24), seems to be higher in FTF than in email because of more personal information exchange. However, personal information exchange in email negotiation could be fostered by a pre-negotiation phone call (Morris et al. 2002).

Cognitive effort, i.e. "the psychological cost that individuals perceive while processing information" (Wang and Doong 2014, p. 741), during negotiation was found to be higher in a synchronous CMC with NSS support compared to FTF or video with NSS support in a salary negotiation (less analyzable), but lower in a better analyzable price negotiation (Wang and Doong 2014).

Finally, different types of an accurate assessment of the opponent are reported in the literature. While there are not too many researchers who have dealt with these variables, their findings point in the same direction: For an accurate assessment of the opponent, FTF seems to be the best available medium. In three parties negotiations, Arunachalam and Dilla (1995) find a higher judgment accuracy about the opponent's specific interests in FTF versus computer-mediated communication (CMC). Griffith and Northcraft (1994) report no difference in integrative judgment accuracy between pencil and paper versus text-based CMC negotiation. Giordano et al. (2007) report a higher deception detection accuracy in FTF versus IM. In a similar vein, Laubert and Parlamis (2019) find consistently low emotion detection accuracy in various text-based electronic negotiations.

Two field studies (Jensen 2009; Townley and Jones 2016) show that both email communication and business letters going back and forth between contractual parties mirror the development of the negotiator relationship during the negotiation and before a deal is closed. "During the three-month period observed, the frequency in use of interpersonal strategies converges as the relationship progresses towards a more contextually stable and more personalized level of communication as trust has been established and power relations have become structured within the legal framework of the contract." (Jensen 2009, p. 4) Both forms of written communication support the provisional amendment of draft agreements, which serve as the main device for reaching a substantive and legal agreement (Townley and Jones 2016).

\subsection{Economic Negotiation Outcomes}

\subsubsection{Agreement}

Economic outcomes in negotiation encompass agreement, individual profits, joint profits, and the dispersion of profits. With regard to agreement, the empirical literature is ambiguous as to which medium fosters or hinders successful completion of a negotiation. Johnson and Cooper (2009a) report a lower probability of agreement in IM versus telephone. In a similar vein, Swaab et al. (2009) find lower exclusion rates for one party in a three party negotiation when parties negotiated FTF (public 
and private) or only publicly in CMC compared to $\mathrm{CMC}$ with private communication only. No differences in agreement rates between different media are reported by McGinn and Keros (2002; FTF, phone, email) and Mahenthiran et al. (1993; pencil and paper, $\mathrm{CMC}$ ). In contrast, higher rates of agreement in email compared to FTF negotiations of an ethically difficult topic were found by van Es et al. (2004). Similarly, Wolfe and McMurthy (2005) report higher rates of agreement for CMC plus NSS support versus FTF for incongruent expectations in regard to subordinate performance between superior and subordinate in budget negotiations, but no media differences for congruent expectations.

\subsubsection{Individual Profit}

Regarding individual profits in distributive or integrative negotiations, only few studies found an effect of different media. In a distributive labor negotiation, Morley and Stephenson $(1969,1970)$ report that negotiators using a constrained phone conversation (no interruptions allowed) were most successful in defending their initial power advantage in respective distributive outcomes compared to FTF (constrained/unconstrained) communication. Lim (2000) reports marginally higher individual profits in FTF compared to communication without visual access. Arunachalam and Dilla (1995) report higher individual profits for FTF compared to CMC negotiators in an integrative three parties negotiation. Barkhi et al. (1999, 2004) find higher individual member rewards in the FTF compared to CMC mode in group negotiations with an unequal power structure between leader and group members. This difference is more pronounced when members have a group incentive compared with an individual incentive (Barkhi et al. 2004), in line with Swaab and colleagues' (2012) communication orientation model and its boundary condition of negotiator orientation. In written only communication, Griffith and Northcraft (1994) find an advantage for pencil and paper over CMC in terms of individual profit. All other reviewed studies that report individual profits, settlement prices in distributive negotiations, or comparable individual outcomes, find no main effect for media on individual profit (Geiger 2014; Giordano et al. 2007; King and Glidewell 1980; Loewenstein et al. 2005; Paese et al. 2003; Rosette et al. 2012; Short 1974; Smith 1969; Suh 1999) or report profit numbers but provide no related significance testing (Kurtzberg et al. 2005a; McGinn and Keros 2002). However, some studies note interaction effects between communication medium and other variables with an impact on individual profit. In a study by Rosette et al. (2012), Hong Kong email sellers reached higher distributive outcomes than Hong Kong FTF and US email and FTF sellers, resembling a culture $\times$ medium interaction. In an early study, Short (1974) found that individual profit for consonant negotiators is higher in FTF and video than in audio, where consonance was conceptualized as point values of the negotiation issues that reflected the actual bargainer's personal beliefs. Greater seller profit in IM than in email were found when the seller used intricate instead of simple arguments (Loewenstein et al. 2005). 


\subsubsection{Joint Profit}

Probably the best covered (see also Fig. 5) and most debated dependent variable in negotiations in different communication media is joint profit or a similar dyadic economic outcome variable (e.g., pareto efficiency). Among the research that reports joint profit, many studies on integrative negotiation find no significant difference on this variable between different communication media conditions (Ang et al. 2013; Calefato et al. 2012; Damian et al. 2000, 2003; Delaney et al. 1997 [when both FTF and CMC negotiators had access to a NSS]; Galin et al. 2007; King and Glidewell 1980; Loewenstein et al. 2005; Naquin and Paulson 2003; Potter and Balthazard 2000; Purdy et al. 2000; Rangaswamy and Shell 1997; Scheck et al. 2008; Schulz and Pruitt 1978; Wachter 1999; Yang 2012). No difference either was found in joint outcomes between email negotiators with or without a $5 \mathrm{~min}$ up front phone call (Morris et al. 2002) as well as for cooperative versus non-cooperative negotiators in CMC negotiation supported by a NSS (Lai et al. 2006) or native versus non-native language negotiators in asynchronous CMC (Lai et al. 2010). Multi-lingual support in synchronous CMC negotiation also did not impact joint outcomes, but the availability of a NSS did (Lim and Yang 2008).

In contrast to these findings, other studies on integrative negotiation report higher joint profit for negotiators without visual access compared to FTF (Carnevale and Isen 1986; Carnevale et al. 1981; Fry 1985 for high-low Machiavellianism dyads only; Lewis and Fry 1977), and higher profits for email versus FTF negotiators (Citera et al. 2005; Croson 1999). Among heterogeneous groups, better negotiation group performance was reached in CMC than FTF, but not in homogeneous groups (Staples and Zhao 2006).

On the contrary, Arunachalam and Dilla $(1992,1995)$ report higher joint profit for FTF negotiators compared to CMC negotiators in a three parties negotiation. These results are mirrored by Diermeier et al.' (2008) results in a three parties coalition negotiation, and they are particularly evident when only private communication was allowed, but not public communication. Hollingshead et al. (1993) report greater joint profit for FTF versus CMC negotiators, and Turnbull et al. (1976) found superior dyadic outcomes for FTF or video compared to audio only. For high-high Machiavellianism dyads, Fry (1985) reports higher joint profits in FTF compared to a negotiation with a visual barrier. Damian et al. (2008) as well as Arthi (2009) show that video conferencing preceded by asynchronous text chat leads to fewer open issues in software requirements negotiation than video conferencing only and thus to better dyadic performance. ${ }^{1}$ Joint profit was also greater in pencil and paper compared to CMC in a study by Mahenthiran et al. (1993).

\footnotetext{
1 Both studies report a rather unusual dyadic outcome measure in their experiments, "number of open issues" in a software requirements negotiation. In this type of negotiation exercise, negotiation issues evolved from the need to steer a software project from beginning to end, i.e. from defining requirements and being able to implement them later. The core negotiation revolved around requirements definition, which later needed to be implemented by the groups. Therefore, the fewer open issues after the focal negotiation, the better for the two parties to the negotiation and the software project.
} 
Sheffield (1995) reports no significant main effects of text versus audio or visual access versus no visual access on joint profit, but an interaction between negotiator orientation (individualistic vs. cooperative) and visual access: The highest joint profit was reached when cooperative negotiators had visual access, independent of whether they used a text based or an audio based medium. These results are deepened by Swaab and colleagues' (2012) meta-analysis who find superior joint outcomes when a visual, an audio, or a synchronous channel was present compared to when this was not the case, and especially when negotiators were neutrally disposed toward each other. For non-cooperative negotiators, this effect reversed, and for cooperative negotiators, no interaction could be found.

If one looks at the different findings on joint gain across the time intervals covered by this review, it is noticeable that the earliest period (1960s to 1990s) provides the greatest spread of outcomes. Four studies find a benefit for no visual access compared to FTF, while five studies find an advantage of FTF against other communication media, with another five studies reporting no statistically significant difference. In the later periods, only one study each finds a benefit or detriment of FTF, while fifteen report no difference between the covered media any more. Together with the weakening research interest on joint profit (see Fig. 5) this observation may be an indication that negotiators' communication practices have changed and that they have adapted to a more diverse array of communication media.

\subsubsection{Dispersion of Profits}

The dispersion of individual profits or the equality of outcomes also feature as a dependent economic variable in some studies. Arunachalam and Dilla (1992, 1995) find higher dispersion of individual profit in CMC than in FTF in a three parties negotiation. Among strangers, but not among friends, McGinn and Keros (2002) also find greater dispersion of profits in email compared to FTF. On the contrary, Croson (1999) finds a lower dispersion of individual outcomes in email compared to FTF negotiation. Again other studies report no differences in the dispersion of individual profits according to different media (Delaney et al. 1997 when FTF and CMC both used a NSS; Lim 2000; Wachter 1999). However, using either a NSS (Delaney et al. 1997; Lim 2000; Lim and Yang 2008)) or a multilingual support tool (Lim and Yang 2008) seems to promote more equal outcomes, independent of the communication channel.

\subsubsection{Boundary Conditions of Economic Outcomes in Text-Based Electronic Negotiation}

In the last two decades, special attention has been cast on text-based electronically mediated negotiations, mostly by email, IM or an internet based chat system. Overall, some boundary conditions helped, and others hindered success in such negotiations. Moore et al. (1999) found that negotiations were more likely to fail when neither a personal relationship nor common in-group status existed between negotiators. In a similar vein, Pesendorfer et al. (2007) and Pesendorfer and Koeszegi (2007) report that personal knowledge of each other and/or social embeddedness 
help handle high intensity conflicts better and increase agreement probability. In a distributive property negotiation conducted via email, where agents represented the principals, disproportionately higher agreement rates were found among agents that were similar and familiar compared to those who were lower in similarity and/or familiarity (Kurtzberg et al. 2005a). Volkema et al. (2010) report a positive correlation between agreement and perceived honesty of the other party in email negotiation. Hine et al. (2009) found that successful e-negotiations contained more positive emotion and agreeable language than failed ones, although they were actually shorter in time. Geiger and Parlamis (2014) show that email comfort, a person's affective attitude towards email, is positively related to joint gain, individual gain and social value in integrative email negotiation. In addition, reactive medium management, i.e. trying to reactively fix shortcomings of the medium, was negatively related to joint profit and social value in email negotiation (Parlamis and Geiger 2015). In electronic text-based communication, some more interaction effects can be witnessed: In a study by Lai et al. (2010), in a native language group the buyer's utility was higher than the seller's, but not in a non-native language group in asynchronous CMC negotiation. In synchronous CMC, negotiators who had access to a NSS reached higher individual outcomes than those without (Lim and Yang 2008), however, no such effect could be found for using a multi-lingual support tool. Kurtzberg and Naquin (2010) write that email negotiators who received emails with a disclaimer statement in an email footer had lower individual and joint outcomes than those receiving email with a confidentiality statement or no statement at all. Ultimately, Kurtzberg et al. (2010) report higher joint profit in email negotiation when they were started with a humorous event compared to when not.

\subsection{Socio-emotional Negotiation Outcomes}

\subsubsection{Negotiator Satisfaction}

Beyond economic negotiation outcomes, some papers also report a variety of socio-emotional outcomes in negotiations conducted in different communication media. As one of the first studies, Carnevale et al. (1981) observe a more positive negotiation atmosphere for negotiators without visual access compared to FTF. Regarding negotiator satisfaction with the negotiation outcome, disparate results are stated: Some papers report highest satisfaction in FTF communication with other media at a disadvantage (Barkhi et al. 1999; Hollingshead et al. 1993; Naquin and Paulson 2003; Wachter 1999 for process but not for outcome satisfaction; Wolfe and Murthy 2005), or higher levels of satisfaction when audio or video channels were present compared to text only (Scheck et al. 2008). Others report greater satisfaction in text-based CMC compared with FTF (Delaney et al. 1997; Geiger 2014; Giordano et al. 2007). Similarly, Pesendorfer and Koeszegi (2006) found higher satisfaction with the outcome in asynchronous versus synchronous computer mediated negotiation. Moreover, a number of papers report no difference in outcome and/or process satisfaction (Ang et al. 2013; Jain and Solomon 2000; Lim and Yang 2008; Purdy et al. 2000; Wang and Doong 2014; 
Yang 2012) for various media and/or support systems (NSS, multi-lingual). The work by Wang and Doong (2014) suggests that the type of negotiation (easily analyzable, difficult to analyze) may interact with the medium to influence process satisfaction: While it is highest in text-based CMC with NSS support for an easily analyzable task, it is lowest for a more difficult one, compared with FTF and video supported by a NSS. Kurtzberg et al. (2010) found that in email negotiation sending a funny cartoon upfront led to greater satisfaction. In NSS supported text-based CMC, perceived control, fairness and collaborative atmosphere of the system enhance negotiator satisfaction (Wang et al. 2010).

Some more papers report constructs related to satisfaction. Wachter (1999) found decreasing outcome affect from FTF through video and audio to CMC. In Jain and Solomon's (2002) paper, FTF provides greater effectiveness of communication and a more positive perception of group processes than CMC. Wolfe and Murthy (2005) report greater task conflict and relational conflict in synchronous CMC with a NSS compared with FTF. Results regarding desire for future interaction partly mirror the results for satisfaction: Naquin and Paulson (2003) find a higher desire for future interaction in FTF than email negotiations. In contrast, no influence of media richness (FTF, video, audio, email) on desire for future interaction when controlling for collaboration and satisfaction was observed by Purdy et al. (2000). Media richness does also not impact the likelihood of renegotiations in practice (Schoop et al. 2008). State anger in FTF versus CMC negotiations seems to be moderated by the type of conflict: in functional conflict it is lower in FTF while in dysfunctional conflict it is higher in FTF compared with CMC (Chen and Tseng 2016).

\subsubsection{Trust}

Trust formation during negotiation seems to be influenced by the medium: Generally, some papers find higher negotiation trust and/or credibility in the opponent in FTF than in email negotiations (Citera et al. 2005; Lu et al. 2017; Naquin and Paulson 2003; Wachter 1999). These findings are mirrored in purchasing processes where trust formation (benevolence, credibility) during FTF negotiations is greater than in email negotiations when procurement complexity is low. However, there are no significant differences between face-to-face and email when procurement complexity is high. (Huang et al. 2008). Similarly, trust was higher in audio plus text or video plus text than in text-only CMC negotiations (Scheck et al. 2008; Yuan et al. 2003). Interestingly, avatar mediated communication witnessed a greater positive change in trustworthiness compared to video (Ang et al. 2013). For email negotiations, emails with a disclaimer message lead to lower trustworthiness than those without or with a confidentiality footer only (Kurtzberg and Naquin 2010) and to higher trust when a funny cartoon is sent compared to when it is not (Kurtzberg et al. 2010). 


\subsubsection{Socio-emotional Evaluation of the Opponent and the Self}

Some socio-emotional evaluations also have to do with the opponent. Positive feelings towards the opponent were greater in dyads that had a 5 min phone conversation and then negotiated via email than those who only negotiated by email (Morris et al. 2002). In a different study, negotiators experienced greater friendliness in asynchronous versus synchronous computer mediated negotiation (Pesendorfer and Koeszegi 2006). Avatar mediated communication witnessed a greater change in opponent likeability compared to video (Ang et al. 2013). Interpersonal awareness did not vary between FTF and electronically multi-media supported negotiations (video, text, document sharing; Damian 2002). In email negotiation, correctly perceiving the opponent's emotion seems very difficult (Laubert and Parlamis 2019). Also in email negotiation, loyalty of an agent to the other agent in agent-agent property negotiations is highest when agents are similar and familiar and seems to go hand in hand with the highest agreement rates (Kurtzberg et al. 2005a). Moreover, negotiators seem to rate their peers worse when the peer appraisal after negotiation is provided by email as compared to pencil and paper (Kurtzberg et al. 2005b).

Finally, some socio-emotional outcomes have to do with the self. Mahenthiran et al. (1993) show that negotiators' perceived autonomy in budget negotiations is greater under pencil and paper versus CMC. Lai et al. (2010) find a higher language self-efficacy and negotiation self-efficacy for native versus non-native e-negotiators.

\subsection{Critical Assessment of Empirical Findings}

The diversity of empirical findings underscores that this research field within group decision and negotiation is still far from consensus as to the effects of different media on most negotiation processes and outcomes. Therefore, the original assumption that FTF is the most suitable communication medium for negotiation, voiced in many theoretical writings and empirically substantiated in some, especially earlier ones, needs to be taken with many grains of salt. As the review of empirical studies shows, only two types of process variables seem to mostly benefit from FTF communication: the formation of trust, including its components of benevolence and credibility, and the accurate assessment of the opponent. For all other process and outcome variables, this review revealed diverging findings. In some instances, FTF produces more cooperative and less competitive behavior, in others it is the other way around. In turn, sometimes differences in outcomes in one or the other direction can be observed; in many instances, no such variations were found.

Social information processing theory and the communication orientation model in negotiation provide some theoretical suggestions as to how some of the diverging findings can be reconciled, e.g. by regarding negotiator orientations (Swaab et al. 2012). Specifically, the communication orientation model suggests that more channels (i.e. audio, visual, synchronicity) benefit initially neutral negotiators, harm non-cooperative negotiators, and do not influence cooperative negotiators in reaching good dyadic outcomes. In addition, several other boundary conditions may be valuable to understand 
differences in negotiation processes and outcomes in various communication media. In media with fewer channels, notably CMC, the review suggests that a personal relationship or similar constructs (social embeddedness, similarity, familiarity) can make up for some of the missing richness in those media (e.g. Pesendorfer et al. 2007). A positive communication style (honesty, agreeable language, humor, positive emotion transmission) and a person's familiarity and comfort with a communication medium may do the same (e.g. Geiger and Parlamis 2014). Other boundary conditions, assessed in past research, include person- or role-specific aspects (culture, Rosette et al. 2012, Machiavellianism, Fry 1985, in-group homogeneity, Staples and Zhao 2006), expectations and incentives (Barkhi et al. 1999, 2004; Mahenthiran et al. 1993), partner similarity and familiarity (Kurtzberg et al. 2005a, b) as well as characteristics of the negotiation task (analyzability, Wang and Doong 2014, type of conflict, Chen and Tseng 2016, complexity, Gattiker et al. 2007).

Beyond various boundary conditions assessed in some empirical papers, several other reasons may be responsible for why the different empirical studies do not fully converge in their results regarding the various dependent variables. First, the timeframe from which this review draws empirical papers is six decades. In these six decades, both the availability and the use of different communication media have dramatically increased. Thus, it is at least questionable whether the same study with a similar sample of test persons would have come to the same results, say, in 1995 and 2015.

Second, while some studies offer differentiated results by explicitly looking at interaction effects between communication medium and other variables, their concrete data collection procedures may implicitly introduce more boundary conditions, not controlled for in this review or earlier meta-analyses (Stuhlmacher and Citera 2005). For example, it may indeed make a difference in results whether a FTF versus IM negotiation study is conducted among tech-savvy engineering students (Damian et al. 2000) or among communication students (Mennecke et al. 2000). Another obvious boundary condition, practically not regarded so far in negotiation studies, is people's attitude towards or preference for a certain communication medium (e.g. Kelly and Keaten 2007).

Third, as the review of empirical findings shows, for many important process and outcome variables, null findings are reported, i.e. no statistically significant differences between media conditions. Interestingly and in contrast to the original studies, all pertinent meta-analyses - although necessarily less fine-grained in differentiating various media - find significant differences in outcomes between various media categories or characteristics. Thus, missing statistical power due to small sample sizes also represents a potential explanation for many of the null findings.

\section{Discussion and Outlook}

\subsection{Current State of Research and Persisting Research Gaps}

This paper has taken stock of six decades of research on the communication medium's influence in negotiation. Various strategic communication and psychological 
theoretical vantage points offer different suggestions as to how using a certain communication medium in negotiation may help or hinder successful processes and outcomes. While a certain convergence of theoretical perspectives can be witnessed over time, both the communication strategic and the social psychological perspectives on communication media in negotiation still fail to offer a unified theoretical framework. The former acknowledges the possibility to use a combination of media, the latter includes the socio-emotional aspects into the discussion; they thereby complement each other. Both perspectives, however, lack a thorough discussion of how communication outcomes in general and negotiation processes and outcomes in particular relate. They also need updating with regard to pertinent boundary conditions.

As the review of the empirical studies shows, media effects on negotiation processes and outcomes seem to depend largely on a number of boundary conditions. Only for two socio-emotional process measures did FTF compared to other media have a positive effect that is mostly independent from boundary conditions. Initially feared disadvantages of leaner media, especially the ones only based on text, can be minimized, e.g. by taking more time, personal relationships, a positive communication style, or a person's familiarity and positive attitude towards the medium. Past research has also identified conditions under which FTF compared to leaner media is advantageous, e.g. when negotiators initially have a neutral orientation toward the opponent, when the negotiation task is difficult or complex rather than simple, or when negotiators are not familiar with the task or partner, yet.

The current state of research also reveals a number of more or less obvious research gaps that have only insufficiently or not at all been addressed. First, the rapid development of more and more differentiated communication media in recent decades combined with the natural use of those media by younger generations, i.e. the digital natives, casts questions as to whom knowledge on communication media and negotiation, gained over the last decades, applies today. For example, if communication patterns between today's teenagers, heavily relying on the use of different features of smartphones and the related apps (e.g. Twenge et al. 2019), are dramatically different from past teenager generations that are twenty or forty years older, why wouldn't these differences also translate into differentiated use of communication media in negotiations in later life stages? The literature shows differentiated media use among younger and older generations, e.g. for email (Metzger and Flanagin 2002); mobile phone and texting (Ishii 2006), or Twitter (Metallo and Agrifoglio 2015). However, several studies also cast in doubt whether generational differences in communication media use behavior actually lead to different communication outcomes between generations, e.g. in learning contexts (Gros et al. 2012; Waycott et al. 2010) or in general psychological well-being (Liu et al. 2019).

Second, nearly all knowledge on the effects of communication media in negotiation stems from studies that allow only one or the other communication medium for a given negotiation task. Both theoretical deliberations (Dennis et al. 2008) and first empirical evidence (Ambrose et al. 2008; Damian et al. 2000, 2003, 2008; Geiger and Laubert 2018; Townley and Jones 2016) show that in real negotiations, various communication media are chosen and used depending on different factors such as stage of the negotiation, communication efficiency, or limiting external factors. The combination of different media may happen in parallel (e.g., Damian et al. 2000, 
2003) or in sequence (e.g., Damian et al. 2008). Additionally, the general availability of different media also poses the question of how negotiators choose their communication media. This topic has been largely neglected in negotiation research (Geiger and Laubert 2018), but already dealt with in the general organizational, communication, or psychological research, (e.g., George et al. 2013; Hertel et al. 2008; Kelly and Keaten 2007; Trevino et al. 1987, 1990, 2000; Webster and Trevino 1995).

Third, the disregard of many important features of real-world negotiations in the reviewed studies represent a persisting research gap. Among others, these features include physical distance between negotiators (e.g., Geiger and Parlamis 2014), different languages (e.g., Lügger et al. 2015), negotiations stretching a longer period of time (e.g. Simonelli 2011), as well as official and unofficial documentation policies (e.g. Spittler and Jentzen 1992).

\subsection{Recent Developments}

Beyond the aforementioned research gaps, new developments in media availability and use contribute additional research needs. What seems to be missing altogether in negotiation research until the present day are accounts of the use of social media (Facebook, Instagram, Twitter, etc.) as well as the use of communication media enhanced by artificial intelligence.

According to Kaplan and Haenlein (2010, p. 61), "Social Media is a group of Internet-based applications that build on the ideological and technological foundations of Web 2.0, and that allow the creation and exchange of User Generated Content." In social media, users can create, share and exchange information in a virtual community (Ngai et al. 2015), transforming 1:1 dialogue into 1:n communication. To the best of the author's knowledge, no negotiation study has yet analyzed in how far social media are or could be used in negotiation processes. Overall, for social media research in negotiation, Ngai et al.' (2015) conclusion, derived in a comprehensive review of social media research in various disciplines, currently also applies: "Notwithstanding, the phenomenon of social media remains new to academia" (p. 33).

Another current topic very closely related to communication media in negotiation, but diligently overlooked in most studies, may profit from recent developments of artificial intelligence (AI) that have passed the fledgling stages: language, in the meaning of mother tongue or foreign language. Language becomes especially important in negotiation when negotiators do not share the same language. In those instances, both negotiators may choose one common foreign language, often English, or one negotiator may choose to communicate in the other negotiator's language if she/he is able to do so. However, this may lead to a disadvantage of the nonnative speaker, e.g. in terms of language self-efficacy, negotiation self-efficacy, or persuasion behavior (Lai et al. 2010). This fact is not very often addressed and only sometimes criticized (e.g. Lügger et al. 2015) in most empirical research, perhaps because it has been predominantly conducted in English speaking countries such as the US, the UK, Canada, or Australia. Moreover, research looking specifically at the influence of language in business negotiations is very sparse (Alvarez et al. 2017; 
Lai et al. 2010; Lim and Yang 2008; Nagler 2018). What could put language center stage in research on communication media in negotiation today, are well-developed translation aids in some channels. Google translator has become very accurate, even in idiomatic translations (the author tried English, French, and German), and Skype now includes a translator for written text as well as for audio, albeit with a slight delay in communication. Thus, for email, instant messaging, audio communication and video conferencing, AI tools are available to bridge language barriers and thus support international negotiation.

\subsection{Future Research}

The current state of theoretical reasoning on communication media in negotiation and its empirical underpinnings as well as the more recent developments offer various avenues for future research. One theoretical challenge that has not yet been solved is the relation between communication outcomes and negotiation processes and outcomes. All the general theoretical perspectives, i.e. those that are not specifically geared toward negotiation, assume mutual understanding of the communicators as the ultimate goal of communication (The social psychological perspectives also have some social outcomes in view). However, mutual understanding is only a necessary, but not a sufficient condition for successful negotiation processes and outcomes. If negotiators reached $100 \%$ mutual understanding on their positions and positional arguments, an agreement would likely be sub-optimal: Understanding was then on the "wrong" type of information. Therefore, reaching the goal of successful communication according to those theoretical perspectives, i.e. mutual understanding, is too little to reach different possible goals in a negotiation, be they distributive and/or integrative. Working out more dependable relations between communication outcomes in general and negotiation processes and outcomes in particular thus remains a theoretical challenge for the field. Media synchronicity theory's distinction between the communication sub-processes of conveyance and convergence may be but a starting point.

With regard to the state of current empirical knowledge and the identified research gaps, several research directions come into mind. Especially in the last two decades, several boundary conditions have been introduced into the research field. Some of them certainly warrant more attention: One promising topic is the relation between a negotiator and the communication medium. Are negotiators with certain attitudes or traits, e.g. introvert versus extrovert people, better served by different media? Which effect do knowledge and use of or preference for specific communication media have on the negotiators' dealings?

A second boundary condition that has proven useful but that has not been fully explored is the type and character of a negotiation. Which role do different aspects of the negotiation task play, e.g. the number of issues, the predictability of outcomes, uncertainty of external factors? Which role do different phases of a negotiation process play? 
As laid out above, the rapid development of communication media over the last three decades (email, instant messaging, text messaging, etc.) has led to differential communication media use among different generations. Whether such generational differences in communication media use make a difference in negotiation is another broad research question worthy of investigation.

Potentially the greatest white spot in the topical field of communication media effects in negotiation is the combination of different media in a negotiation. Combination of media can happen either in parallel or in sequence. The number of available media today and the different possibilities of combination across a negotiation and potentially its phases offer numerous possibilities for research, with potentially great value for practice.

Also from a practical perspective, questions pertaining to (sometimes limiting) features of real-world negotiations, and how communication media interact with them, offer important research questions. Which influence does real physical distance have on the choice and use of communication media and respective negotiation processes and outcomes? How do language barriers between international negotiators play out in different media? Which role does the communication medium play in negotiation processes stretching over a longer period of time? Which role do documentation policies, e.g. leaving or avoiding a paper trail, have on communication media choice, use, and effects?

Finally, recent developments in the use of social media and AI may inspire research on the communication medium's role in negotiation. In how far social media can be and are used in negotiation, as suggested by the introductory example of US president Trump's tweet aimed at Kim of North Korea, is but one question worthy of investigation. Another interesting research question may be how the composition, size and type of audience that communicators allow in their social media activities influence social media use and effectiveness in negotiation. Such analysis may draw on and connect with negotiation research dealing with constituencies (e.g., Steinel et al. 2009) and with research on public and private communication (Diermeier et al. 2008). Other interesting questions pertain to certain features of different social media, such as the permanence or vanishing of social media content, exemplified by Facebook and Snapchat, respectively.

Several research questions pertaining to the use of AI in bridging language differences can be imagined. For example, do language support tools for nonnative speakers have differentiated effects in different media or may one medium be especially conducive to language-aided negotiation among non-native speakers (e.g. Jensen 2009)? In which communication media do language stereotypes play a role in negotiation (e.g. Alvarez et al. 2017)? When language support tools are used, does the chosen language for negotiation play a role?

Ultimately, this review shows that despite a peak of research in the 2000s, many more interesting research questions on the interplay between communication media and negotiation lay ahead of us.

Funding Open Access funding enabled and organized by Projekt DEAL. 
Open Access This article is licensed under a Creative Commons Attribution 4.0 International License, which permits use, sharing, adaptation, distribution and reproduction in any medium or format, as long as you give appropriate credit to the original author(s) and the source, provide a link to the Creative Commons licence, and indicate if changes were made. The images or other third party material in this article are included in the article's Creative Commons licence, unless indicated otherwise in a credit line to the material. If material is not included in the article's Creative Commons licence and your intended use is not permitted by statutory regulation or exceeds the permitted use, you will need to obtain permission directly from the copyright holder. To view a copy of this licence, visit http://creativecommons.org/licen ses/by/4.0/.

\section{References}

Alvarez CMO, Taylor KA, Gomez C (2017) The effects of Hispanic bilinguals language use and stereotype activation on negotiations outcomes. J Bus Res 72:158-167

Ambrose E, Marshall D, Fynes B, Lynch D (2008) Communication media selection in buyer-supplier relationships. Int J Oper Prod Manag 28:360-379

Ang CS, Bobrowicz A, Siriaraya P, Trickey J, Winspear K (2013) Effects of gesture-based avatar-mediated communication on brainstorming and negotiation tasks among younger users. Comput Hum Behav 29:1204-1211

Angiolillo JS, Blanchard HE, Israelski EW (1993) Video telephony. AT\&T Technol J 72:7-20

Arthi B (2009) Distributed requirements negotiations using mixed media. Int J Eng Technol 1:474-480

Arunachalam V, Dilla WN (1992) Computer-mediated communication and structured interaction in transfer pricing negotiation. J Inf Syst 6:149-170

Arunachalam Y, Dilla WN (1995) Judgment accuracy and outcomes in negotiation: a causal modeling analysis of decision-aiding effects. Organ Behav Hum Dec Process 61:289-304

Balliet D (2009) Communication and cooperation in social dilemmas: a meta-analytic review. J Confl Resolut 54:39-57

Baltes BB, Dickson MW, Sherman MP, Bauer CC, LaGanke JS (2002) Computer-mediated communication and group decision making: a meta-analysis. Organ Behav Hum Dec Process 87:156-179

Barkhi R, Jacob VS, Pirkul H (1999) An experimental analysis of face to face versus computer mediated communication channels. Group Decis Negot 8:325-347

Barkhi R, Jacob VS, Pirkul H (2004) The influence of communication mode and incentive structure on GDSS process and outcomes. Decis Support Syst 37:287-305

Calefato F, Damian D, Lanubile F (2012) Computer-mediated communication to support distributed requirements elicitations and negotiations tasks. Empir Softw Eng 17:640-674

Carnevale PJD, Isen AM (1986) The influence of positive affect and visual access on the discovery of integrative solutions in bilateral negotiation. Organ Behav Hum Dec Process 37:1-13

Carnevale PJD, Pruitt DG, Seilheimer SD (1981) Looking and competing: accountability and visual access in integrative bargaining. J Personal Soc Psychol 40:111-120

Chen IS, Tseng F-T (2016) The relevance of communication media in conflict contexts and their effectiveness: a negotiation experiment. Comput Hum Behav 59:134-141

Citera M, Beauregard R, Mitsuya T (2005) An experimental study of credibility in e-negotiations. Psychol Mark 22:163-179

Clark HH, Brennan SE (1991) Grounding in communication. In: Resnick LB, Levin JM, Teasley SD (eds) Perspectives on socially shared cognition. American Psychological Association, Washington, DC, pp 127-149

Cooper RB, Johnson NA (2014) So close yet no agreement: the effects of threats to self-esteem when using instant messaging and audio during seller-buyer negotiations. Decis Support Syst 57:115-126

Croson RTA (1999) Look at me when you say that: an electronic negotiation simulation. Simul Gaming 30:23-37

Curhan JR, Elfenbein HA, Kilduff GJ (2009) Getting off on the right foot: subjective value versus economic value in predicting longitudinal job outcomes from job offer negotiations. J Appl Psychol 94:524-534. https://doi.org/10.1037/a0013746

Daft RL, Lengel RH (1984) Information richness: a new approach to managerial behavior and organization design. Res Organ Behav 6:191-233 
Daft RL, Lengel RH (1986) Organization information requirements, media richness, and structural design. Manag Sci 32:554-571

Damian D (2002) An empirical study of a multimedia group support system for distributed software requirements meetings. e-Serv $\mathrm{J}$ 1:43-60

Damian D, Eberlein A, Shaw MLG, Gaines BR (2000) Using different communication media in requirements negotiation. IEEE Softw 17:28-36

Damian D, Eberlein A, Shaw MLG, Gaines BR (2003) An exploratory study of facilitation in distributed requirements engineering. Requir Eng 8:23-41

Damian D, Lanubile F, Mallardo T (2008) On the need for mixed media in distributed requirements negotiations. IEEE Trans Softw Eng 34:116-132

Delaney MM, Foroughi A, Perkins WC (1997) An empirical study of the efficacy of a computerized negotiation support system (NSS). Decis Support Syst 20:185-197

Dennis AR, Fuller RM, Valacich JS (2008) Media, tasks, and communication processes: a theory of media synchronicity. MIS Q 32:575-600

Dennis AR, Fuller RM, Valacich JS (2009) Media synchronicty and media choice: choosing media for performance. In: Hartmann T (ed) Media choice-a theoretical and empirical overview. Routledge, New York, pp 247-273

Diermeier D, Swaab RI, Medvec VH, Kern MC (2008) The micro-dynamics of coalition formation. Polit Res Q 61:484-501

Dorado MA, Medina FJ, Munduate L, Cisneros IFJ, Euwema M (2002) Computer-mediated negotiation of an escalated conflict. Small Group Res 33:509-524

Duthler KW (2006) The politeness of requests made via email and voicemail: support for the hyperpersonal model. J Comput Mediat Commun 11:500-521

Friedman RA, Currall SC (2003) Conflict escalation: dispute exacerbating elements of e-mail communication. Hum Relat 56:1325-1347

Fry WR (1985) The effect of dyad machiavellianism and visual access on integrative bargaining outcomes. Personal Soc Psychol Bull 11:51-62

Galin A, Gross M, Gosalker G (2007) E-negotiation versus face-to-face negotiation what has changed-if anything? Comput Hum Behav 23:787-797

Gattiker TF, Huang X, Schwarz JL (2007) Negotiation, email, and Internet reverse auctions: how sourcing mechanisms deployed by buyers affect suppliers' trust. J Oper Manag 25:184-202

Geiger I (2014) Media effects on the formation of negotiator satisfaction: the example of face-to-face and text based electronically mediated negotiations. Group Decis Negot 23:735-763

Geiger I, Laubert C (2018) Situational strategic versus personal influences on negotiation medium choice-media synchronicity theory and affect for communication channel. Int J Confl Manag 29:398-423

Geiger I, Parlamis J (2014) Is there more to email negotiation than email? The role of email affinity. Comput Hum Behav 32:67-78

George JF, Carlson JR, Valacich JS (2013) Media selection as a strategic component of communication. MIS Q 37:1233-A1234

Giordano GA, Stoner JS, Brouer RL, George JF (2007) The influences of deception and computer-mediation on dyadic negotiations. J Computer Mediat Commun 12:362-383

Graf A, Koeszegi Sabine T, Pesendorfer EM (2010) Electronic negotiations in intercultural interfirm relationships. J Manag Psychol 25:495-512

Griessmair M, Koeszegi ST (2009) Exploring the cognitive-emotional fugue in electronic negotiations. Group Decis Negot 18:213-234

Griffith TL, Northcraft GB (1994) Distinguishing between the forest and the trees: media, features, and methodology in electronic communication research. Organ Sci 5:272-285

Gros B, Garcia I, Escofet A (2012) Beyond the net generation debate: a comparison between digital learners in face-to-face and virtual universities. Int Rev Res Open Distr Learn 13:190-210

Hatta T, Ohbuchi K-i, Fukuno M (2007) An experimental study on the effects of exitability and correctability on electronic negotiation. Negot J 23:283-305

Hertel G, Schroer J, Batinic B, Naumann S (2008) Do shy people prefer to send e-mail? Personality effects on communication media preferences in threatening and nonthreatening situations. Soc Psychol 39:231-243

Hine MJ, Murphy SA, Weber M, Kersten G (2009) The role of emotion and language in dyadic e-negotiations. Group Decis Negot 18:193-211 
Hollingshead AB, McGrath JE, O'Connor K (1993) Group task performance and communication technology: a longitudinal study of computer-mediated versus face-to-face work groups. Small Group Res 24:307-333

Huang X, Gattiker TF, Schwarz JL (2008) Interpersonal trust formation during the supplier selection process: the role of the communication channel. J Supply Chain Manag 44:53-75

Ishii K (2006) Implications of mobility: the uses of personal communication media in everyday life. J Commun 56:346-365

Jain BA, Solomon JS (2000) The effect of task complexity and conflict handling styles on computersupported negotiations. Inf Manag 37:161-168

Jensen A (2009) Discourse strategies in professional e-mail negotiation: a case study. Engl Specif Purp 28:4-18

Johnson NA, Cooper RB (2009a) Media, affect, concession, and agreement in negotiation: IM versus telephone. Decis Support Syst 46:673-684

Johnson NA, Cooper RB (2009b) Power and concession in computer-mediated negotiations: an examination of first offers. MIS Q 33:147-170

Kaplan AM, Haenlein M (2010) Users of the world, unite! The challenges and opportunities of Social Media. Bus Horiz 53:59-68

Kelly L, Keaten JA (2007) Development of the affect for communication channels scale. J Commun 57:349-365

Kiesler S, Siegel J, McGuire TW (1984) Social psychological aspects of computer-mediated communication. Am Psychol 39:1123-1134

Kiesler S, Sproull L (1992) Group decision making and communication technology. Organ Behav Hum Dec Process 52:96-123

King DC, Glidewell JC (1980) Dyadic bargaining outcomes under individualistic and competitive orientations. Hum Relat 33:781-803

Koeszegi S, Pesendorfer E-M, Vetschera R (2011) Data-driven phase analysis of E-negotiations: an exemplary study of synchronous and asynchronous negotiations. Group Decis Negot 20:385-410

Koeszegi ST, Srnka KJ, Pesendorfer E-M (2006) Electronic negotiations - a comparison of different support systems. Die Betriebswirtschaft 66:441-463

Kurtzberg TR, Naquin CE (2010) Electronic signatures and interpersonal trustworthiness in online negotiations. Negot Confl Manag Res 3:49-63

Kurtzberg T, Dunn-Jensen L, Matsibekker CLZ (2005a) Multi-party negotiations: agents, alliances, and negotiation success. Int J Confl Manag 16:245-264

Kurtzberg TR, Naquin CE, Belkin LY (2005b) Electronic performance appraisals: the effects of e-mail communication on peer ratings in actual and simulated environments. Organ Behav Hum Dec Process 98:216-226

Kurtzberg TR, Naquin CE, Belkin Liuba Y (2010) Humor as a relationship-building tool in online negotiations. Int J Confl Manag 20:377-397

Lai H, Doong H-S, Kao C-C, Kersten G (2006) Negotiators' communication, perception of their counterparts, and performance in dyadic e-negotiations. Group Decis Negot 15:429-447

Lai H, Lin W-J, Kersten GE (2010) The importance of language familiarity in global business e-negotiation. Electron Commer Res Appl 9:537-548

Latané B (1981) The psychology of social impact. Am Psychol 36:343-356

Laubert C, Parlamis J (2019) Are you angry (happy, sad) or aren't you? Emotion detection difficulty in email negotiation. Group Decis Negot 28:377-413

Lea M, Spears R (1992) Paralanguage and social perception in computer-mediated communication. J Organ Comput 2:321-341

Lewis SA, Fry WR (1977) Effects of visual access and orientation on the discovery of integrative bargaining alternatives. Organ Behav Hum Perform 20:75-92

Lim J (2000) An experimental investigation of the impact of NSS and proximity on negotiation outcomes. Behav Inf Technol 19:329-338

Lim J, Yang YP (2008) Exploring computer-based multilingual negotiation support for English-Chinese dyads: can we negotiate in our native languages? Behav Inf Technol 27:139-151

Liu D, Baumeister RF, Yang C-C, Hu B (2019) Digital communication media use and psychological well-being: a meta-analysis. J Comput Mediat Commun 24:259-273

Loewenstein J, Morris MW, Chakravarti A, Thompson L, Kopelman S (2005) At a loss for words: dominating the conversation and the outcome in negotiation as a function of intricate arguments and communication media. Organ Behav Hum Dec Process 98:28-38 
Lu SC, Kong DT, Ferrin DL, Dirks KT (2017) What are the determinants of interpersonal trust in dyadic negotiations? Meta-analytic evidence and implications for future research. J Trust Res 7:22-50

Lügger K, Geiger I, Neun H, Backhaus K (2015) When East meets West at the bargaining table: adaptation, behavior and outcomes in intra- and intercultural German-Chinese business negotiations. J Busi Econ 85:15-43

Mahenthiran S, Greenberg PS, Greenberg RH (1993) The impact of computer-mediated communication on the processes and outcomes of negotiated transfer pricing. Account Manag Inf Technol 3:229-248

Matheson K (1991) Social cues in computer-mediated negotiations: gender makes a difference. Comput Hum Behav 7:137-145

McGinn KL, Keros AT (2002) Improvisation and the logic of exchange in socially embedded transactions. Admin Sc Q 47:442-473

McGrath JE, Hollingshead AB (1993) Putting the 'group' back in group support systems: some theoretical issues about dynamics in groups with technological enhancements. In: Jessup LM, Valacich JS (eds) Group support systems: new perspectives. Macmillan, New York, pp 78-96

Mennecke BE, Valacich JS, Wheeler BC (2000) The effects of media and task on user performance: a test of the task-media fit hypothesis. Group Decis Negot 9:507-529

Metallo C, Agrifoglio R (2015) The effects of generational differences on use continuance of Twitter: an investigation of digital natives and digital immigrants. Behav Inf Technol 34:869-881

Metzger MJ, Flanagin AJ (2002) Audience orientations toward new media. Commun Res Rep 19:335-338

Moore DA, Kurtzberg TR, Thompson LL, Morris MW (1999) Long and short routes to success in electronically mediated negotiations: group affiliations and good vibrations. Organ Behav Hum Dec Process 77:22-43

Morley IE, Stephenson GM (1969) Interpersonal and inter-party exchange: a laboratory simulation of an industrial negotiation at the plant level. Br J Psychol 60:543-545

Morley IE, Stephenson GM (1970) Formality in experimental negotiations: a validation study. Br J Psychol 61:383-384

Morris M, Nadler J, Kurtzberg T, Thompson L (2002) Schmooze or lose: social friction and lubrication in e-mail negotiations. Group Dyn Theory Res Pract 6:89-100

Nagler H (2018) Zum moderierenden Einfluss von Fremdsprache in internationalen Geschäftsverhandlungen. ESCP Europe, Berlin

Naquin CE, Paulson GD (2003) Online bargaining and interpersonal trust. J Appl Psychol 88:113-120

Ngai EWT, Tao SSC, Moon KKL (2015) Social media research: theories, constructs, and conceptual frameworks. Int J Inf Manag 35:33-44

Paese PW, Schreiber AM, Taylor AW (2003) Caught telling the truth: effects of honesty and communication media in distributive negotiations. Group Decis Negot 12:537-566

Parlamis JD, Geiger I (2015) Mind the medium: a qualitative analysis of email negotiation. Group Decis Negot 24:359-381

Pesendorfer E-M, Graf A, Koeszegi S (2007) Relationship in electronic negotiations: tracking behavior over time. Z. Betriebswirtschaft 77:1315-1338

Pesendorfer E-M, Koeszegi S (2006) Hot versus cool behavioural styles in electronic negotiations: the impact of communication mode. Group Decis Negot 15:141-155

Pesendorfer E-M, Koeszegi S (2007) Social embeddedness in electronic negotiations. Group Decis Negot 16:399-415

Potter RE, Balthazard PA (2000) Supporting integrative negotiation via computer mediated communication technologies. J Int Consum Mark 12:7-32

Purdy JM, Nye P, Balakrishnan PV (2000) The impact of communication media on negotiation outcomes. Int J Confl Manag 11:162-187

Rangaswamy A, Shell GR (1997) Using computers to realize joint gains in negotiations: toward an 'electronic bargaining table'. Manag Sci 43:1147-1164

Rosette AS, Brett JM, Barsness Z, Lytle AL (2012) When cultures clash electronically: the impact of email and social norms on negotiation behavior and outcomes. J Cross-Cult Psychol 43:628-643

Scheck S, Allmendinger K, Hamann K (2008) The effects of media richness on multilateral negotiations in a collaborative virtual environment. J Media Psychol 20:57-66

Schoop M, Köhne F, Staskiewicz D, Voeth M, Herbst U (2008) The antecedents of renegotiations in practice—an exploratory analysis. Group Decis Negot 17:127-139 
Schulz JW, Pruitt DG (1978) The effects of mutual concern on joint welfare. J Exp Soc Psychol $14: 480-492$

Sheffield J (1995) The effect of communication medium on negotiation performance. Group Decis Negot 4:159-179

Short JA (1974) Effects of medium of communication on experimental negotiation. Hum Relat 27:225-234

Short J, Williams E, Christie B (1976) The social psychology of telecommunications. Wiley, London

Simonelli NM (2011) Bargaining over international multilateral agreements: the duration of negotiations. Int Interact 37:147-169. https://doi.org/10.1080/03050629.2011.568845

Smith DH (1969) Communication and Negotiation Outcome. J Commun 19:248-256

Sokolova M, Shah M, Szpakowicz S (2006) Comparative analysis of text data in successful face-to-face and electronic negotiations. Group Decis Negot 15:127-140

Spears R, Lea M (1994) Panacea or panopticon? The Hidden power in computer-mediated communication. Commun Res 21:427-445

Spittler JR, Jentzen GH (1992) Dispute resolution: managing construction conflict with step negotiations. AACE Int Trans 1:D-9

Sproull L, Kiesler S (1986) Reducing social context cues: electronic mail in organizational communication. Manag Sci 32:1492-1512

Staples DS, Zhao L (2006) The effects of cultural diversity in virtual teams versus face-to-face teams. Group Decis Negot 15:389-406

Steinel W, De Dreu CKW, Ouwehand E, Ramírez-Marín JY (2009) When constituencies speak in multiple tongues: the relative persuasiveness of hawkish minorities in representative negotiation. Organ Behav Hum Dec Process 109:67-78

Stuhlmacher AF, Citera M (2005) Hostile behavior and profit in virtual negotiation: a meta-analysis. J Bus Psychol 20:69-93

Stuhlmacher AF, Citera M, Willis T (2007) Gender differences in virtual negotiation: theory and research. Sex Roles 57:329-339

Suh KS (1999) Impact of communication medium on task performance and satisfaction: an examination of media-richness theory. Inf Manag 35:295-312

Swaab RI, Kern MC, Diermeier D, Medvec V (2009) Who says what to whom? The impact of communication setting and channel on exclusion from multiparty negotiation agreements. Soc Cogn 27:385-401

Swaab RI, Galinsky AD, Medvec V, Diermeier DA (2012) The communication orientation model: explaining the diverse effects of sight, sound, and synchronicity on negotiation and group decision-making outcomes. Personal Soc Psychol Rev 16:25-53

Townley A, Jones A (2016) The role of emails and covering letters in negotiating a legal contract: a case study from Turkey. Engl Specif Purp 44:68-81

Trevino LK, Lengel RH, Daft RL (1987) Media symbolism, media richness, and media choice in organizations - a symbolic interactionist perspective. Commun Res 14:553-574

Trevino LK, Lengel RH, Bodensteiner W, Gerloff EA, Muir NK (1990) The richness imperative and cognitive style: the role of individual differences in media choice behavior. Manag Commun Q 4:176-197

Treviño LK, Webster J, Stein EW (2000) Making connections: complementary influences on communication media choices attitudes, and use. Organ Sci 11:163-182

Turnbull AA, Strickland L, Shaver KG (1976) Medium of communication, differential power, and phasing of concessions: negotiating success and attributions to the opponent. Hum Commun Res 2:262-270

Twenge JM, Martin GN, Spitzberg BH (2019) Trends in US Adolescents' media use, 1976-2016: the rise of digital media, the decline of TV, and the (near) demise of print. Psychol Pop Media Cult 8:329

Van Es R, French W, Stellmaszek F (2004) Resolving conflicts over ethical issues: face-to-face versus internet negotiations. J Bus Ethics 53:165-172

Vinciarelli A, Salamin H, Polychroniou A (2014) Negotiating over mobile phones: calling or being called can make the difference. Cogn Comput 6:677-688

Volkema R, Fleck D, Hofmeister A (2010) Predicting competitive-unethical negotiating behavior and its consequences. Negot J 26:263-286

Volkema RJ, Fleck D, Hofmeister A (2011) Getting Off on the Right Foot: the effects of initial email messages on negotiation Process and Outcome. IEEE Trans Prof Commun 54:299-313 
Wachter RM (1999) The effect of gender and communication mode on conflict resolution. Comput Hum Behav 15:763-782

Walther JB (1992) Interpersonal effects in computer-mediated interaction: a relational perspective. Commun Res 19:52-59

Walther JB (1994) Anticipated ongoing interaction versus channel effects on relational communication in computer-mediated interaction. Hum Commun Res 20:473-501

Wang H-C, Doong H-S (2014) Revisiting the task-media fit circumflex: a further examination of negotiation tasks. Inf Manag 51:738-746

Wang Z, Lim J, Guo X (2010) Negotiator satisfaction in NSS-facilitated negotiation. Group Decis Negot 19:279-300

Waycott J, Bennett S, Kennedy G, Dalgarno B, Gray K (2010) Digital divides? Student and staff perceptions of information and communication technologies. Comput Edu 54:1202-1211

Webster J, Trevino LK (1995) Rational and social theories as complementary explanations of communication media choices: two policy-capturing studies. Acad Manag J 38:1544-1572

Wolfe CJ, Murthy US (2005) Negotiation support systems in budget negotiations: an experimental analysis. J Manag Inf Syst 22:351-381

Yang G (2012) Analyzing computer mediated buyer-seller negotiations: an application of social presence theory. Int J Mark Bus Commun 1:25-35

Yuan Y, Head M, Du M (2003) The effects of multimedia communication on web-based negotiation. Group Decis Negot 12:89-109

Zornoza A, Ripoll P, Peiró JM (2002) Conflict management in groups that work in two different communication contexts: face-to-face and computer-mediated communication. Small Group Res 33:481-508

Publisher's Note Springer Nature remains neutral with regard to jurisdictional claims in published maps and institutional affiliations. 